Argonne $\mathbf{A}$

\title{
An Analytical Model of Erosive Wear of BioMass Comminution Components
}

Applied Materials Division 


\begin{abstract}
About Argonne National Laboratory
Argonne is a U.S. Department of Energy laboratory managed by UChicago Argonne, LLC under contract DE-AC02-06CH11357. The Laboratory's main facility is outside Chicago, at 9700 South Cass Avenue, Lemont, Illinois 60439. For information about Argonne and its pioneering science and technology programs, see www.anl.gov.
\end{abstract}

\title{
DOCUMENT AVAILABILITY
}

Online Access: U.S. Department of Energy (DOE) reports produced after 1991 and a growing number of pre-1991 documents are available free at OSTI.GOV (http://www.osti.gov/),

a service of the US Dept. of Energy's Office of Scientific and Technical Information.

Reports not in digital format may be purchased by the public from the National Technical Information Service (NTIS):

U.S. Department of Commerce

National Technical Information Service

5301 Shawnee Road

Alexandria, VA 22312

www.ntis.gov

Phone: (800) 553-NTIS (6847) or (703) 605-6000

Fax: (703) 605-6900

Email: orders@ntis.gov

Reports not in digital format are available to DOE and DOE contractors from the Office of Scientific and Technical Information (OSTI):

U.S. Department of Energy

Office of Scientific and Technical Information

P.O. Box 62

Oak Ridge, TN 37831-0062

www.osti.gov

Phone: (865) 576-8401

Fax: (865) 576-5728

Email: reports@osti.gov

\section{Disclaimer}

This report was prepared as an account of work sponsored by an agency of the United States Government. Neither the United States Government nor any agency thereof, nor UChicago Argonne, LLC, nor any of their employees or officers, makes any warranty, express or implied, or assumes any legal liability or responsibility for the accuracy, completeness, or usefulness of any information, apparatus, product, or process disclosed, or represents that its use would not infringe privately owned rights. Reference herein to any specific commercial product, process, or service by trade name, trademark, manufacturer, or otherwise, does not necessarily constitute or imply its endorsement, recommendation, or favoring by the United States Government or any agency thereof. The views and opinions of document authors expressed herein do not necessarily state or reflect those of the United States Covernment or any agency thereof, Argonne National Laboratory, or UChicago Argonne, LLC. 


\section{An Analytical Model of Erosive Wear of BioMass Comminution Components}

by

George Fenske and Oyelayo Ajayi

Applied Materials Division, Argonne National Laboratory

for

Energy Efficiency and Renewable Energy

Bioenergy Technologies Office

October 2020 



\section{CONTENTS}

ABSTRACT/EXECUTIVE SUMMARY …................................................................. v

1 INTRODUCTION/BACKGROUND ......................................................................... 1

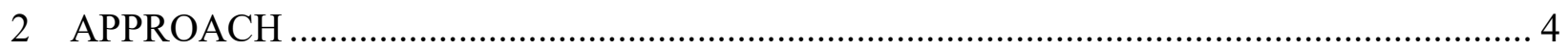

3 RESULTS OF APPLICATION TO MONODISPERSE PARTICLES ................................ 7

4 VALIDATION OF MODEL AGAINST INL AWT EXPERIMENTAL DATA ................... 9

4.1 Particle Size Distribution .................................................................................... 10

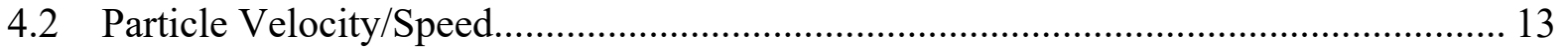

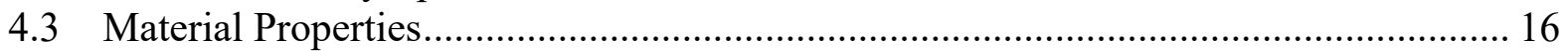

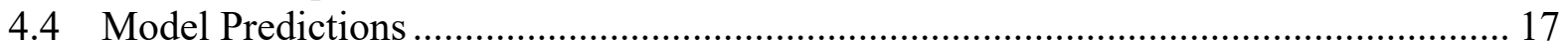

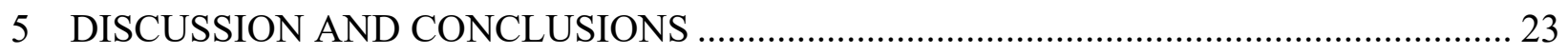

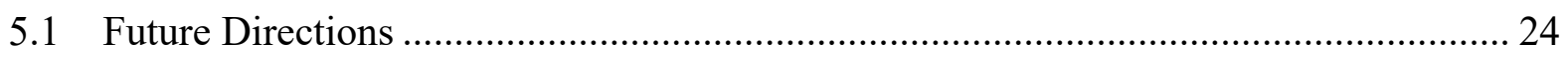

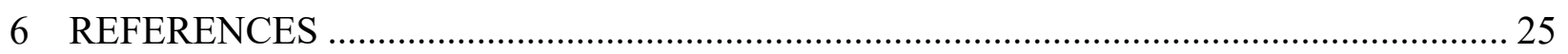

\section{FIGURES}

1 Unit operations used during pretreatment of feedstock prior to low-temperature

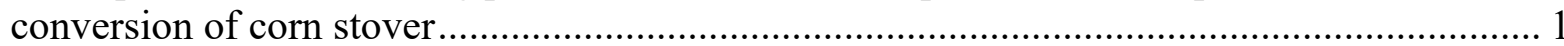

2 Wear of plug screw feeder components and stage- 1 hammer mills .................................. 2

3 Illustration of QbD process for modeling component wear as functions of feedstock CMAs, hammer CMAs, and unit processing parameters, CPPs to wear................. 4

4 Illustration of parallel and perpendicular components of particle impingement associated with 'cutting' and 'deformation' mechanisms ............................................. 5

5 Predicted erosion rates for $100-\mathrm{m} / \mathrm{s}, 100-\mu \mathrm{m}$ diameter $\mathrm{SiO}_{2}$ particles incident on

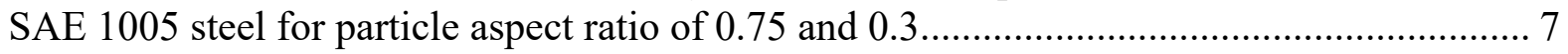

6 Predicted erosion rates for $100-\mathrm{m} / \mathrm{s}, 100-\mu \mathrm{m}$ diameter $\mathrm{SiO}_{2}$ particles incident on

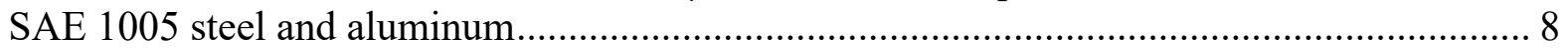

7 Impact of particle speed on erosion rate for $50-\mu \mathrm{m} \mathrm{SiO}_{2}$ particles..................................... 8

8 Wear as a function of impingement angle for three different particle sizes .......................... 8

9 Photo of grit blaster nozzle used to simulate abrasive wear by biomass feedstock................ 9

10 Measured mass loss of AWT test coupon per unit mass of biomass feedstock for INL AWT tests. 


\section{FIGURES (CONT.)}

11 Coupon wear rate derived from INL AWT wear tests, assuming a density of $7.8 \mathrm{~g} / \mathrm{cm}^{3}$ for coupon material. Wear data for LALM corn stover were not available, nor was ash content for AWT LM pine residue runs. ...................................... 10

12 Measured particle size distribution of inorganic particles in low-ash corn stover ............... 11

13 Particle size distributions of corn stover and pine residue feedstock: experimental

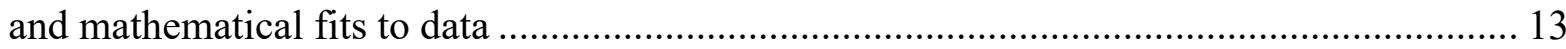

14 Speed of corn stover particles exiting grit blaster nozzle ................................................ 14

15 Speed of pine residue particles exiting grit blaster nozzle............................................... 14

16 Comparison of predicted wear and measured wear for corn stover and pine residue

17 Sensitivity study on effect of hardness on predicted wear rate of high-ash corn stover.

18 Sensitivity study on effect of toughness on predicted wear rate of high-ash corn stover......

19 Sensitivity study on effect of fatigue ductility coefficient on predicted wear rate of high-ash corn stover

20 Sensitivity study on effect of fatigue ductility exponent on predicted wear rate of high-ash corn stover

21 Sensitivity study on effect of particle shape factor on predicted wear rate of high-ash corn stover

22 Comparison of predicted versus measured wear for high- and low-ash corn stover: baseline, 3.93 GPA; $20 \mathrm{~kJ} / \mathrm{m}^{2}$; $\epsilon f, 1.1 ; \mathrm{b}, 0.6 ; \eta, 0.8$; and $3.93 \mathrm{GPA} ; 10 \mathrm{~kJ} / \mathrm{m}^{2}$; $\epsilon f$, $1.1 ;$ b. $0.65 ; \eta, 0.6$

\section{TABLES}

1 Average, standard deviation, skewness, and kurtosis of inorganic particle size distributions

2 Estimation of air speed at nozzle exit and coupon face ............................................. 15

3 Feedstock and Material Properties Used in Abrasion/Erosion Wear Model ........................ 16

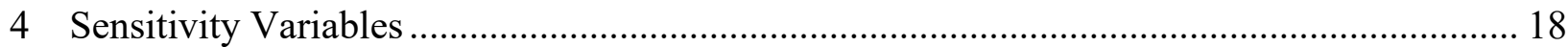

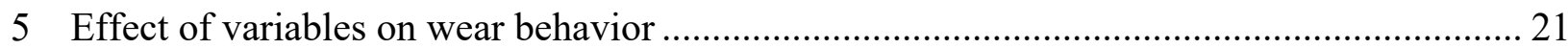




\begin{abstract}
EXECUTIVE SUMMARY
An analytical erosion model that relates critical process parameters (speed and impingement angle) to critical material attributes of inorganic mineral species in feedstock (density, size, aspect ratio) and substrate (hardness, toughness, and fatigue ductility) was applied to model wear in pretreatment milling operations. Results of the model were compared to experimental measurements of wear produced using the Accelerated Wear Test (AWT) rig at Idaho National Laboratory (INL). Results showed that there is good agreement between predicted and measured performance, and that a quality-by-design (QbD) tool can be developed to predict component reliability based on scientific engineering principles in lieu of trial-anderror approaches.
\end{abstract}


This page left intentionally blank. 


\section{INTRODUCTION/BACKGROUND}

There is considerable interest worldwide in developing processes to transform nonfood sources of biomass into bioproducts, biofuels, and bioenergy. The U.S. Department of Energy's Bioenergy Technologies Office supports activities to develop innovative technologies for converting biomass into usable products, fuels, and energy, including activities on Feedstock Supply \& Logistics (FSL), Agal Biofuels, Sustainability, Analysis, and Conversion Technologies [1]. Recognizing the importance of pretreatment of biomass feedstocks on the development of value-added products [2-4], the Feedstock Conversion Interface Consortium (FCIC; https://fcic.inl.gov) develops first principles-based knowledge and tools to understand the effects of biomass properties and process variability on pretreatment operations.

Pretreatment of biomass feedstocks is an essential step in changing the structure of lignocellulosic fractions into a state that responds to enzymatic hydrolysis. Pretreatment processes involve a number of unit operations requiring milling, grinding, cutting, and mechanical transport of feedstock from one stage to another. Because of the nature of mechanical interactions between feedstock (and ash) and surfaces of materials of construction, wear can occur and limit the reliability and functionality/performance of critical unit operations.

Figure 1 illustrates the different unit operations associated with preprocessing of corn stover for low-temperature conversion to ethanol. Virtually all the operations are potential sites for wear and degradation. Operations highlighted in blue are units on which significant wear has been

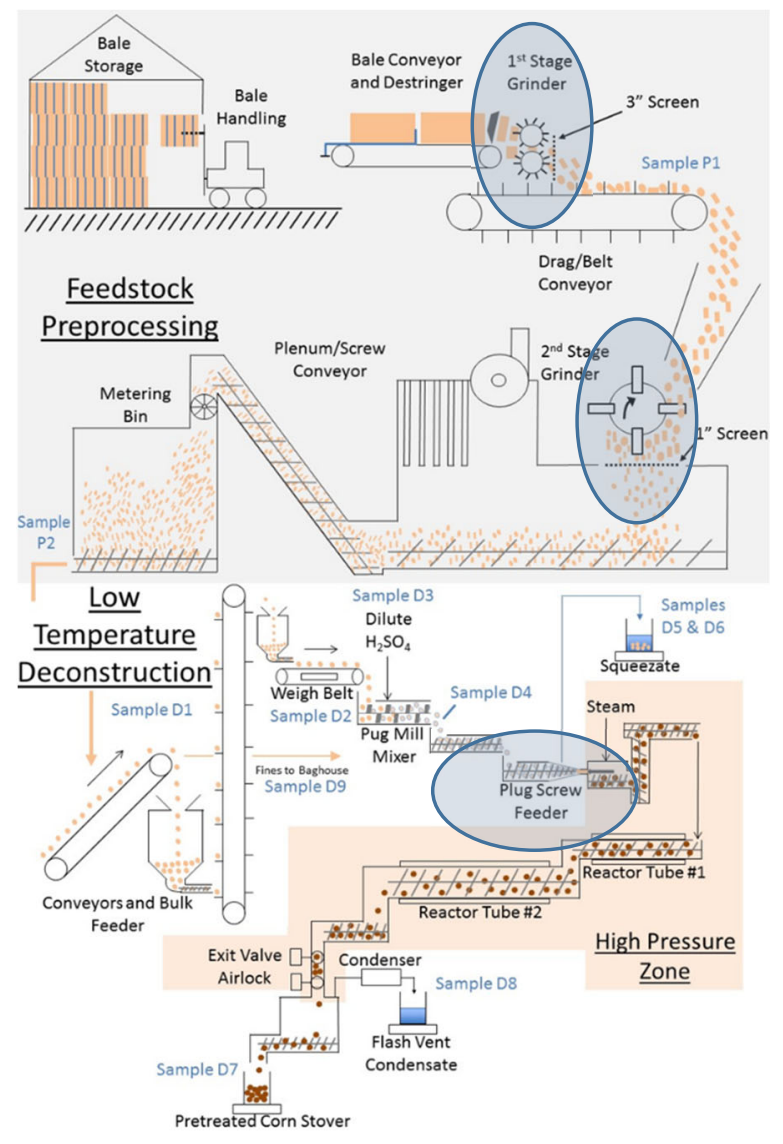

FIGURE 1 Unit operations used during pretreatment of feedstock prior to lowtemperature conversion of corn stover (courtesy Erik Kuhn - National Renewable Energy Laboratory) observed. These units include grinders (first- and second-stage hammer mills) and plug screw feeders used to form a pressure plug between the atmospheric operations and the high-pressure zone.

Examples [5] of wear observed in grinding and plug screw feeding are shown in the highlighted regions in Figure 2 [6]. The flutes of the screw for the worn screw feeder are visibly smaller, and the leading edge for the hammer is rounded. Analysis of the worn surfaces $[7,8]$ suggests particle abrasion/erosion and micropolishing are major causes of the observed wear. 
Abrasion and erosion are complex phenomena that are dependent on the nature of the material (biomass feedstock and entrained ash) causing the wear and on the nature of the material undergoing wear (material and mechanical properties of materials of construction) and on operating /process parameters (speed, temperature, loads, and so on). The current approach to addressing wear commonly starts by using components designed for other applications (e.g., paper and pulp) that treat feedstock with significantly different attributes or processing parameters or Edisonian trial-and-error testing of materials. Both approaches have merit; however, an ability to predict wear based on critical material attributes and critical process parameters has great potential for more effective design and engineering of unit operation processes.

The results presented here report on efforts to apply a mechanistic model of wear
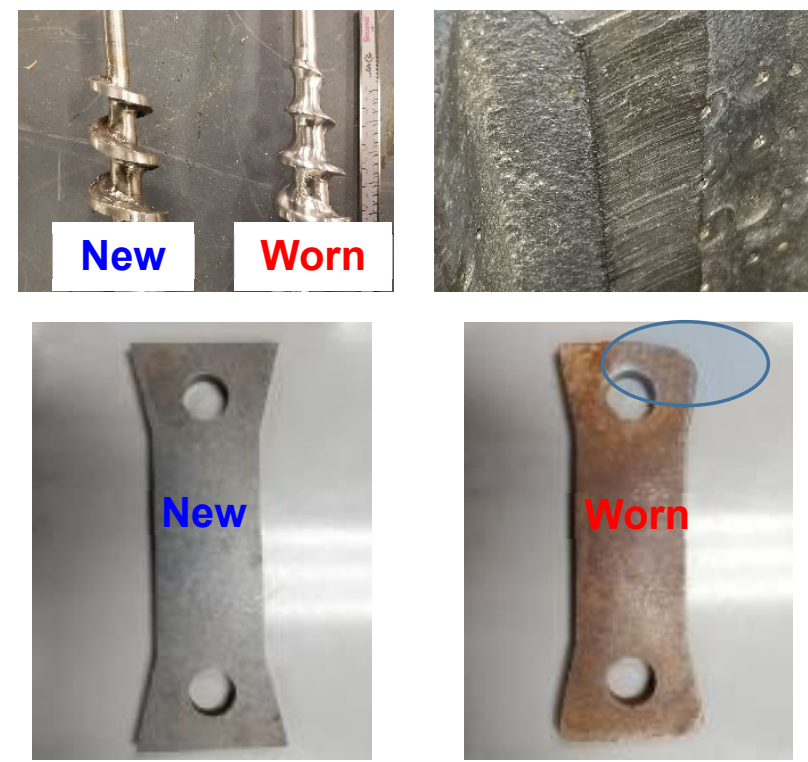

FIGURE 2 Wear of plug screw feeder components (top) and stage-1 hammer mills (bottom) (courtesy M. Tucker, National Renewable Energy Laboratory, and N. Yancey, Idaho National Laboratory) based on physical mechanisms involved in abrasion and erosion processes to predict wear of the stage 1 hammers used in the Process Development Unit (PDU) at the INL Biomass Feedstock National User Facility (https://bfnuf.inl.gov/SitePages/ Process\%20Development\%20Unit.aspx).

The model is based on the assumption that erosive wear of the hammer is dominated by extrinsic inorganic minerals transported along with the biomass feedstock [9]. Following a QbD approach, commonly used in the development of pharmaceutical products [10], a QbD model is developed that relates critical feedstock properties (inorganic particle size distribution, aspect ratio, particle composition/density, loading/ash content), critical material attributes (CMAs) of the hammer (hardness, toughness, fatigue ductility), and critical process parameters (CPPs) (speed, impingement angle/geometrical configuration) to predict the volumetric wear rate (cubic millimeters per unit mass of biomass) of the hammer (critical quality attribute [CQA]). The QbD model predictions are subsequently compared to bench erosion studies performed by INL using an AWT rig [11,12] to simulate erosive wear of biomass feedstock with intrinsic and extrinsic ash.

The remaining sections of the report are organized as follows:

1. Approach. Description of the approach, QbD, and analytical model developed by BenAmi to predict material wear due to erosion of surfaces during impact by energetic particles. 
2. Results. Sensitivity studies of the model to illustrate the effect of particle and material attributes (particle size, shape and density, substrate hardness, toughness, and fatigue ductility), and process parameters (speed and angle of impingement) for model materials and monodisperse particle sizes.

3. Validation. Comparison of model predictions against wear simulation data using the INL AWT rig with corn stover and pine residue feedstocks.

4. Discussion of results and discrepancies between predicted and measured results, and areas for future activities (modeling wear of actual hammers). 


\section{APPROACH}

The QbD approach was adapted to identify cause-and-effect relationships between CMAs, CPPs, and CQAs in an overall process flow diagram of a preprocessing stream. The output (CQA) of a unit operation serves as an input (CMA) of the next operation. Figure 3 shows the $\mathrm{CbD}$ flow diagram for the stage 1 hammer mill. The analysis follows this approach and involves detailed analysis of feedstock CMAs, hammer CMAs, and processing CPPs to predict hammer wear CQAs. The CbD process utilizes constitutive models developed by Ben Ami to calculate the CQA (wear) as functions of the CMAs and CPPs.

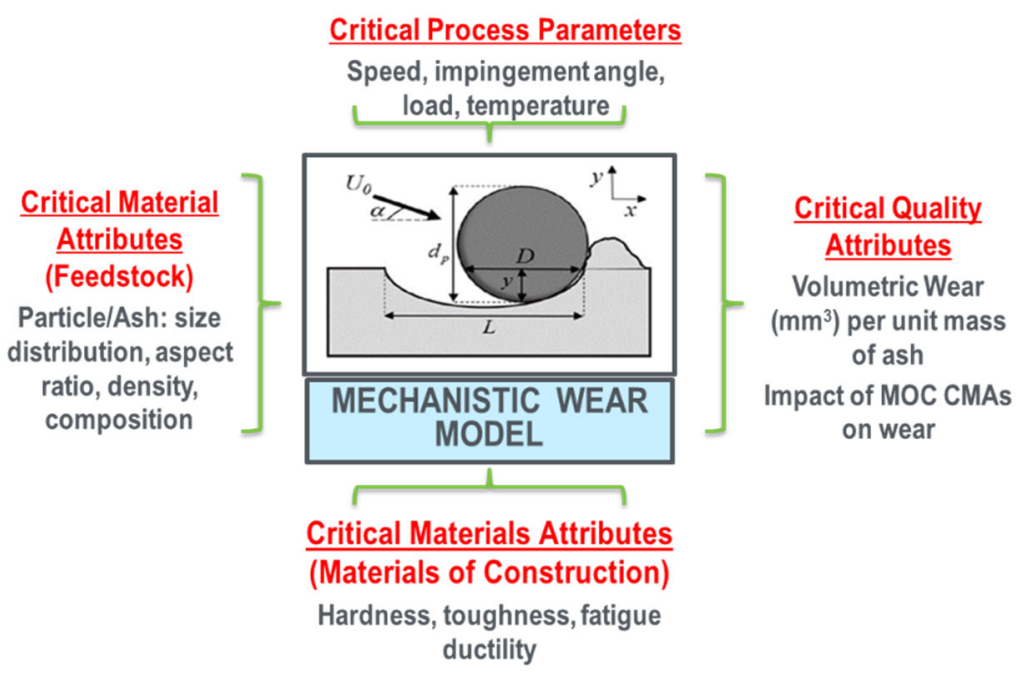

FIGURE 3 Illustration of QbD process for modeling component wear as functions of feedstock CMAs, hammer CMAs, and unit processing parameters, CPPs to wear (CQAs)

Key to the $\mathrm{QbD}$ approach is the development of constitutive equations that relate volumetric wear to critical material properties, feedstock properties, and process parameters. Fortunately, we do not need to start from scratch to develop the constitutive relations; the study of wear of components used in comminution of minerals and biomass is not new, and the fundamental mechanisms are well known. General reviews of solid particle erosion and abrasive wear mechanisms can be found in ASM handbook articles [13,14]. Mayer-Laigle et al. provide a focused review of comminution of lignocellolosic biomass [15]. The theoretical treatments selected for this task date back to early 1960s articles by Finnie [16] and by Bitter [17], followed by articles by Hutchings [18] and Huang et al. [19], and more recently articles by Arabnejad at el. [20] and Ben-Ami et al. [21].

The analytical approach selected is based on the assumption that erosion is due to two main mechanisms, "cutting" and "deformation," terms that are somewhat misleading and often create confusion. The cutting term actually refers to mechanisms associated with particles 
impacting at oblique angles to the surface (e.g., motion and energy parallel to a surface), while deformation refers to mechanisms associated with motion perpendicular to the surface (see Figure 4).

Following the semimechanistic approach developed by Ben-Ami [21], the volumetric wear volume (volume of material worn per incident particle) due to an impact of a particle with the surface is calculated as the sum of wear lost to cutting mechanisms (motion parallel to the surface) and deformation mechanisms (motion perpendicular to the surface):

$$
\Delta Q_{T}=\Delta Q_{D}+\Delta Q_{C}
$$

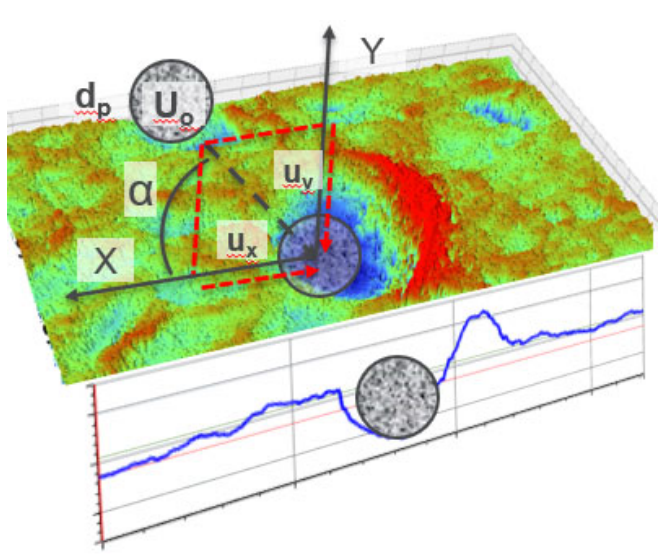

FIGURE 4 Illustration of parallel and perpendicular components of particle impingement associated with 'cutting' and 'deformation' mechanisms [21]

where

$\Delta Q_{T}=$ the total volume lost due to particle impact,

$\Delta Q_{D}=$ the volume lost to repeated deformation events arising from the normal component of a particle impacting a surface, and

$\Delta Q_{C}=$ the cutting component arising from the horizontal motion of a particle.

Constitutive relations were developed by Ben-Ami to relate $\Delta Q_{D}$ and $\Delta Q_{C}$ to feedstock properties (density of incident particles, particle size distribution, and ash content ${ }^{1}$ ), material (hammer) properties (hardness, toughness, and fatigue ductility), and process parameters (speed and angle of impingement). The models take into account the following parameters:

$H \quad$ target material hardness, $\mathrm{Pa}$

$R \quad$ target material fracture toughness, $\mathrm{J} / \mathrm{m}^{2}$

$\varepsilon f \quad$ fatigue ductility coefficient

$b \quad$ fatigue ductility exponent

$d \quad$ particle diameter, $\mathrm{m}$

$\eta \quad$ particle shape factor $(0-1)$

$\rho$ density, $\mathrm{kg} / \mathrm{m}^{3}$

$\alpha \quad$ particle impingement angle rad

$U$ particle impact velocity, $\mathrm{m} / \mathrm{s}$

$f \quad$ model empirical exponent

$C_{C} \quad$ semi-empirical model coefficient

$C_{D} \quad$ semi-empirical model coefficient material of construction CMA material of construction CMA material of construction CMA material of construction CMA feedstock CMA feedstock CMA feedstock CMA operation CPP operation CPP

\footnotetext{
${ }^{1}$ Ideally we prefer to use a particle content, number of inorganic particles of a given size per unit mass. In lieu of this, we use the ash content, percentage of inorganic ash after firing at $750^{\circ} \mathrm{C}$.
} 
Ploughing and fracture mechanisms were included in model for cutting wear, $\Delta Q_{C}$, which yielded the following relationship for wear associated with the horizontal portion of particle velocity:

$$
\frac{\Delta Q_{C}}{m_{p}}=C_{c}(1+f)\left[1-\exp \left(-200 \alpha^{2}\right)\right] \frac{\left(\frac{\rho_{p} d_{p}^{2}}{\eta}\right)^{(1-f) / 2}}{H^{\left(\frac{1+f}{2}\right)} R^{(1-f)}} U_{0}^{3-f} \cos ^{2}(\alpha) \sin ^{1-f}(\alpha)
$$

The deformation wear related to the normal component of particle impact is based on Hutchings treatment [18] that assumes the deformation erosion is caused by crack propagation arising from repeated plastic deformation and incorporates a fatigue fracture model (CoffinMason) criteria for low-cycle fatigue. The deformation wear rate (per unit particle mass) is given as

$$
\frac{\Delta Q_{D}}{m_{p}}=C_{D} \frac{\rho_{p}^{1 / 4 b}}{\eta^{3 / 4 b} \varepsilon_{f}^{1 / b} H^{(1+1 / 4 b)}}\left[U_{0} \sin (\alpha)\right]^{2+1 / 2 b}
$$

The coefficients $C_{D}$ and $f$ depend on material hardness and toughness, while $C_{C}$ is independent of hardness, toughness, or fatigue parameters. Ben-Ami presented the following relations based on correlations of erosion wear data for aluminum alloys, copper alloys, and different grades of iron and steel:

$$
\begin{gathered}
f=\frac{14}{\ln \left(\frac{537 H}{R}\right)}-1 \\
C_{D}=0.002(H / R)^{0.7} \\
C_{C}=0.0136
\end{gathered}
$$

The model requires material properties on hardness, toughness, fatigue ductility coefficient, fatigue ductility exponent, particle shape, particle density, and particle velocity to predict wear. The following discussion illustrates the sensitivity of the model to different parameters for a baseline material (SAE 1055) and aluminum. 


\section{RESULTS OF APPLICATION TO MONODISPERSE PARTICLES}

Examples of the model are presented to illustrate the impact of key particle and material CMAs: one example related to feedstock attributes (particle shape), a second example of the impact of material properties (hardness, toughness, fatigue ductility), and a third example of a process property (speed). The initial studies assumed monosized particles - all particles have the same size/diameter and particle shape. Figure 5 shows the effect of particle shape/aspect factor, $\eta$, on wear rate for $100-\mathrm{m} / \mathrm{s}, 100-\mu \mathrm{m}$ particles with a shape factor of 0.75 or 0.3 . The shape factor is the ratio of the effective particle diameter, $d_{e f f}$, to the particle diameter, $d_{p}$; a small aspect ratio is representative of particles with sharp/angular surfaces, while particles with large aspect ratios $(\eta \approx 1)$ are more spherical. As shown in Figure 5, particles of the same size and speed but with different aspect ratios exhibit different wear rates; sharp, angular particles wear more than spherical particles.
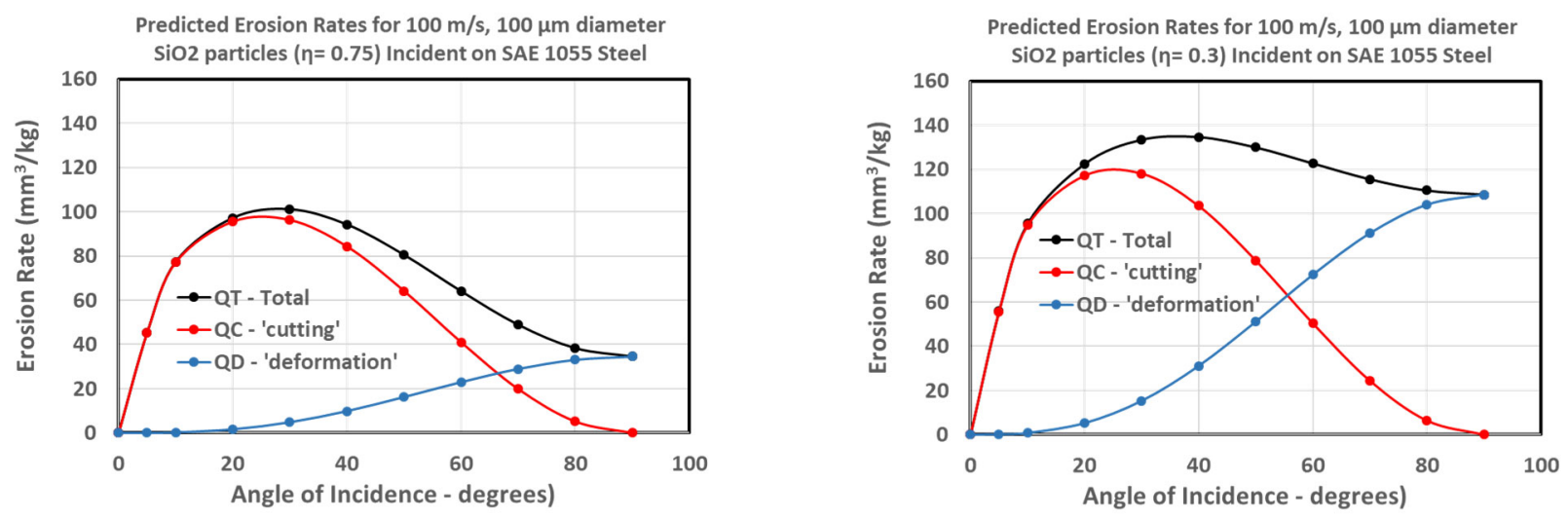

FIGURE 5 Predicted erosion rates for $100-\mathrm{m} / \mathrm{s}, 100-\mu \mathrm{m}$ diameter $\mathrm{SiO}_{2}$ particles incident on $\mathrm{SAE}$ 1005 steel for particle aspect ratio of (left) 0.75 and (right) 0.3

The effect of substrate material properties (hardness, toughness, and fatigue ductility) are illustrated in Figure 6, which shows deformation $\left(\Delta Q_{D} / m_{p}\right)$, cutting $\left(\Delta Q_{C} / m_{p}\right)$, and total $\left(\Delta Q_{T} / m_{p}\right)$ wear rates (cubic millimeter per kilogram of particles) for a hardened SAE 1055 steel and a softer aluminum substrate for $100-\mu \mathrm{m}$ silicon dioxide $\left(\mathrm{SiO}_{2}\right)$ particles incident at $100 \mathrm{~m} / \mathrm{s}$ with an aspect ratio of 0.75 .

As expected, the softer aluminum is predicted to wear more than the steel substrate; in this case, the peak erosion rate of aluminum is predicted to be approximately four times faster than that of steel. Another aspect to note is the location of the peak erosion rate as a function of impingement angle; that is, the peak rate for steel occurs at $30^{\circ}$, while the peak rate for aluminum occurs at $10^{\circ}$. 

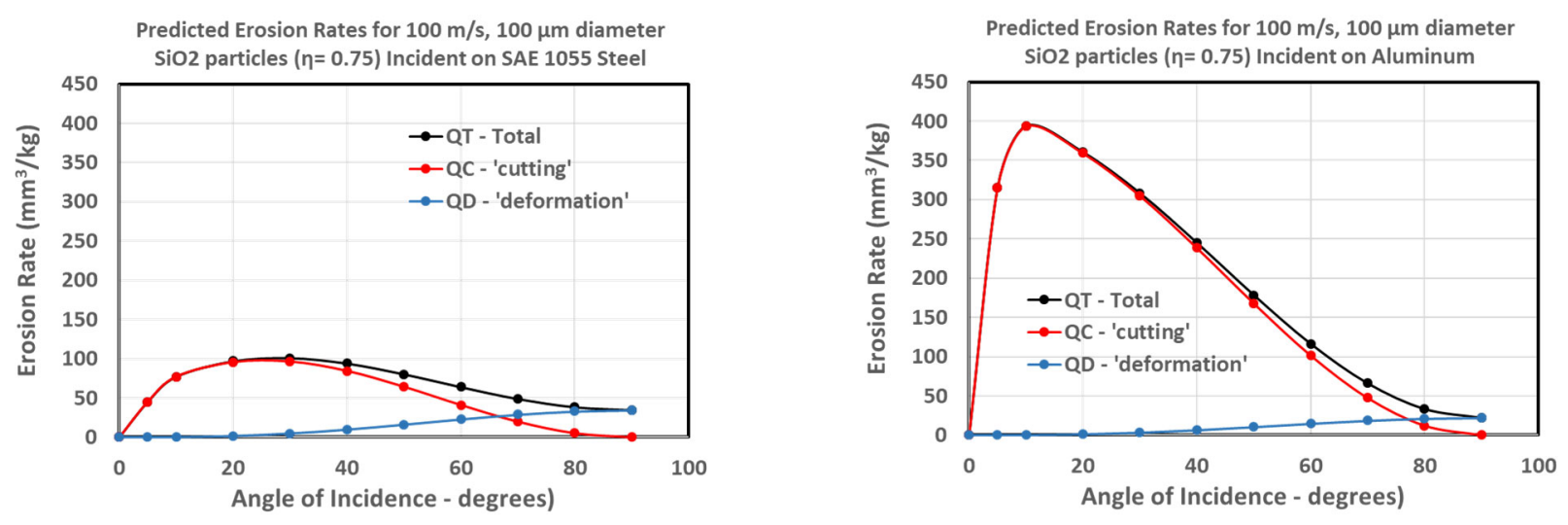

FIGURE 6 Predicted erosion rates for $100-\mathrm{m} / \mathrm{s}, 100-\mu \mathrm{m}$ diameter $\mathrm{SiO}_{2}$ particles incident on (left) SAE 1005 steel and (right) aluminum

The effect of particle speed for $100-\mu \mathrm{m}-$ diameter $\mathrm{SiO}_{2}$ particles incident on steel (SAE $1055)$ is shown in Figure 7. Because of a strong velocity dependence, where $\Delta Q$ is approximately proportional to (velocity) [2], a doubling of speed results in more than four times greater wear.

Figure 8 shows the effect of particle diameter on the wear rate (total wear, $Q_{T}$; cutting wear, $Q_{C}$; and deformation wear, $\left.Q_{D}\right)$ as a function of impingement angle for a material with properties prototypic of stage 1 hammers (400 Knoop hardness, $25 \mathrm{~kJ} / \mathrm{m}^{2}$ toughness, and a fatigue ductility coefficient of 1.1. The data shown are for an incident particle speed of $250 \mathrm{~m} / \mathrm{s}$ with curves shown for three particle diameters, 255, 505, and $1005 \mu \mathrm{m}$. Since the deformation wear rate, $Q_{D}$, is independent of particle diameter (Eq. 3), all three curves for $Q_{D}$ fall on top of a single curve, with the maximum occurring at $90^{\circ}$. The cutting wear rate, $Q_{C}$, (Eq. 2), however, is

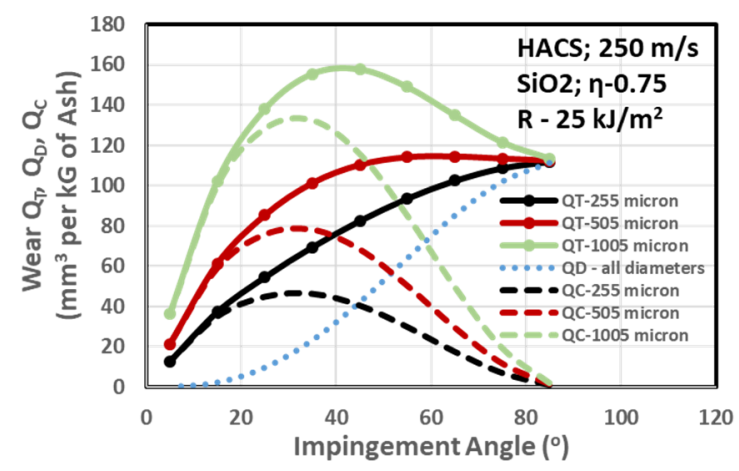

FIGURE 8 Wear as a function of impingement angle for three different particle sizes $(255,505$, and 1005 micron)

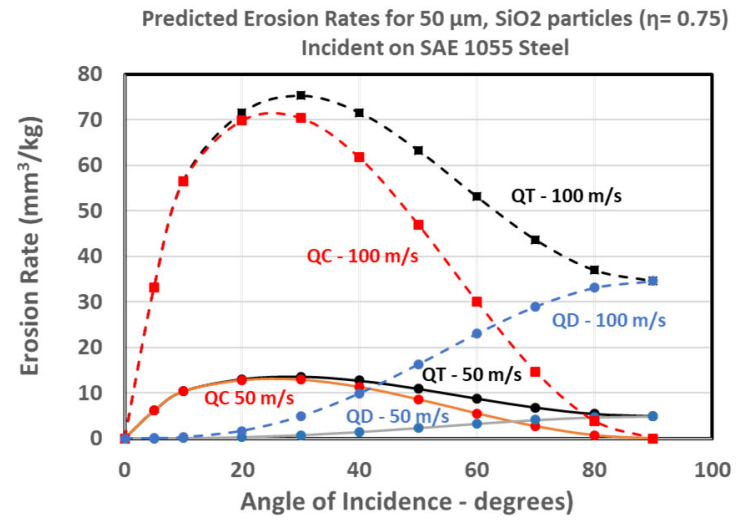

FIGURE 7 Impact of particle speed on erosion rate for $50-\mu \mathrm{m} \mathrm{SiO}_{2}$ particles dependent on the particle diameter, and thus there are three separate curves, each with a peak rate occurring around $30^{\circ}$. The total wear, $Q_{T}$, which is the sum of the $Q_{C}$ and $Q_{D}$, may or may not exhibit a peak wear rate depending on the particle diameter. The total wear produced by smaller particles is dominated by $Q_{D}$, while total wear for midsized and large particles is influenced more by cutting wear and exhibits peaks as a function of impingement angle [ $Q_{T}$ for $255-\mu \mathrm{m}$ particles increases monotonically, while $Q_{T}$ for $1,005-$ and $505-\mu \mathrm{m}$ particles exhibits peaks, more so for $1005-\mu \mathrm{m}$ particles. 


\section{VALIDATION OF MODEL AGAINST INL AWT EXPERIMENTAL DATA}

The results above apply to predicted wear behavior and sensitivity of the behavior to CMAs of the several critical model parameters. The results use parameters developed by Ben-Ami et al. [21] to model results published by Huang et al. [19]. To validate the models, the results were compared against experimental simulation of wear arising from biomass (corn stover and pine residue) fed through a grit blaster nozzle onto test coupons. Figure 9 shows a picture of the INL AWT rig used to simulate erosive wear caused by the impact of biomass feedstock media on mechanical components in preprocessing equipment [22]. Details of the AWT test technique and results have been submitted for

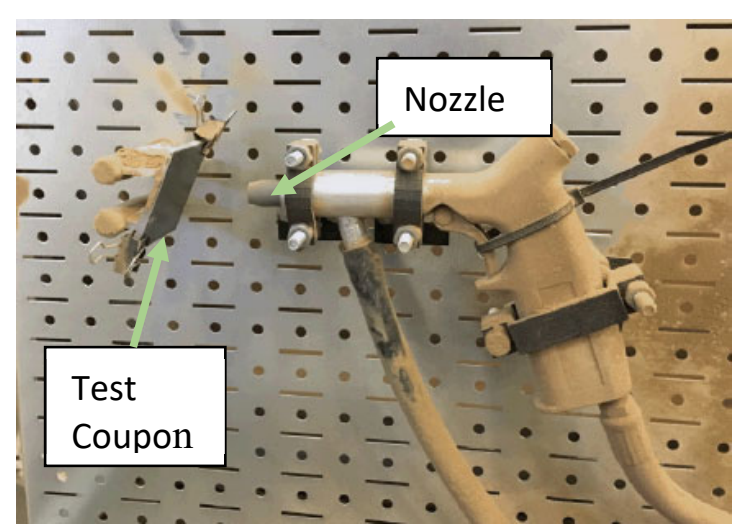

FIGURE 9 Photo of grit blaster nozzle used to simulate abrasive wear by biomass feedstock (courtesy INL [22]) publication [23]. The air pressure feeding the nozzle was held constant at $65 \mathrm{psig}$ for all runs. Tests were performed on coupon segments extracted from stage 1 hammers and exposed to approximately $1 / 2 \mathrm{~kg}$ of biomass feedstock. Mass losses were obtained from weight measurements before and after each test. Two tests were performed for each impingement angle. Weight loss measurements (milligrams) were converted to volumetric losses (cubic millimeters) assuming a density of $7.8 \mathrm{~g} / \mathrm{cm}^{3}$ for the stage 1 hammer. Results of measured wear as a function of impingement angle for different feedstocks (corn stover and pine residue) are summarized in Figure 10 for tests with corn stover and pine residue [24].
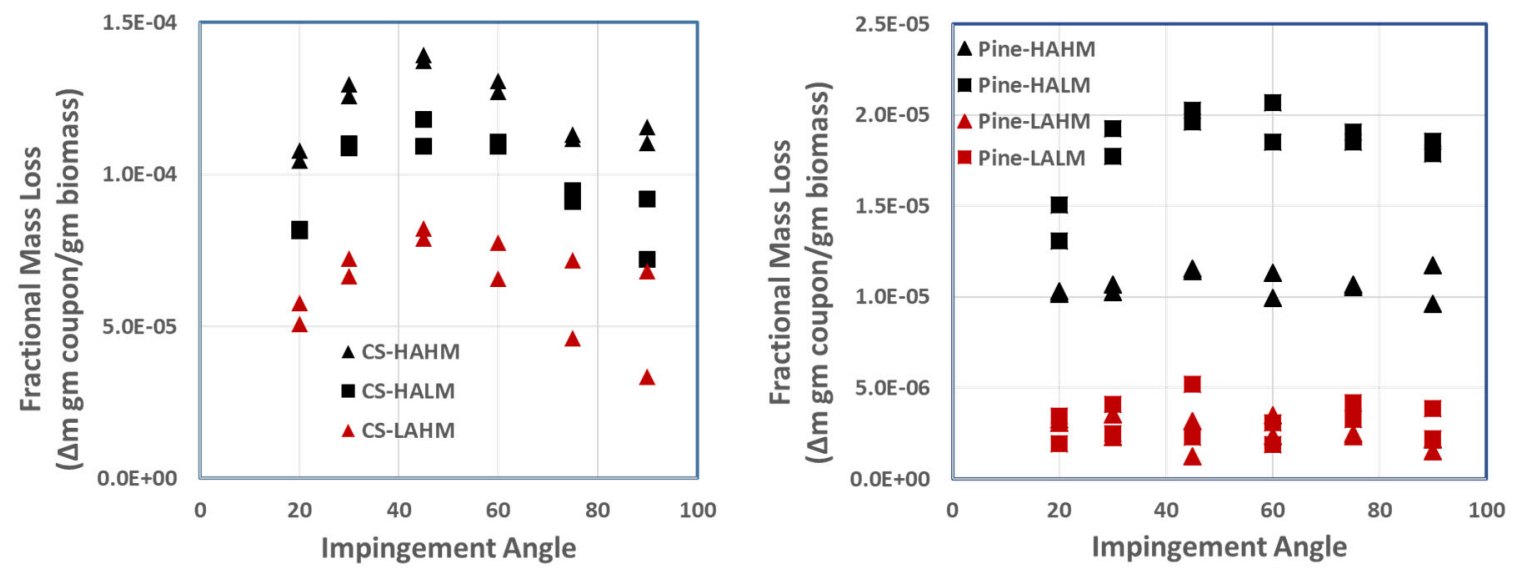

FIGURE 10 Measured mass loss of AWT test coupon per unit mass of biomass feedstock for INL AWT tests 
Figure 10 shows a significant difference in wear rate based on mass loss per unit mass of biomass. The results in Figure 10 suggest corn stover is much more abrasive than pine residue; however, the ash content of the corn stover was approximately 10 times that of the pine residue, and thus the higher wear rate for the corn stover is a reflection of the higher ash/mineral content (which to a large degree is extrinsic inorganic minerals) in the corn stover.

Figure 11 shows the wear rate (volumetric wear) normalized to the ash content. As shown, when adjusted on wear per unit mass of ash (a measure of the inorganic mineral content), the wear rates are quite similar. Although the wear rates on a per-unit-ash content are now similar, there are differences in the shapes of the curves. While the corn stover exhibits a more traditional erosion/impingement dependence with a peak in wear occurring around $45^{\circ}$, the pine residue exhibits a flatter dependence on impingement angle with a higher fluctuation in data.
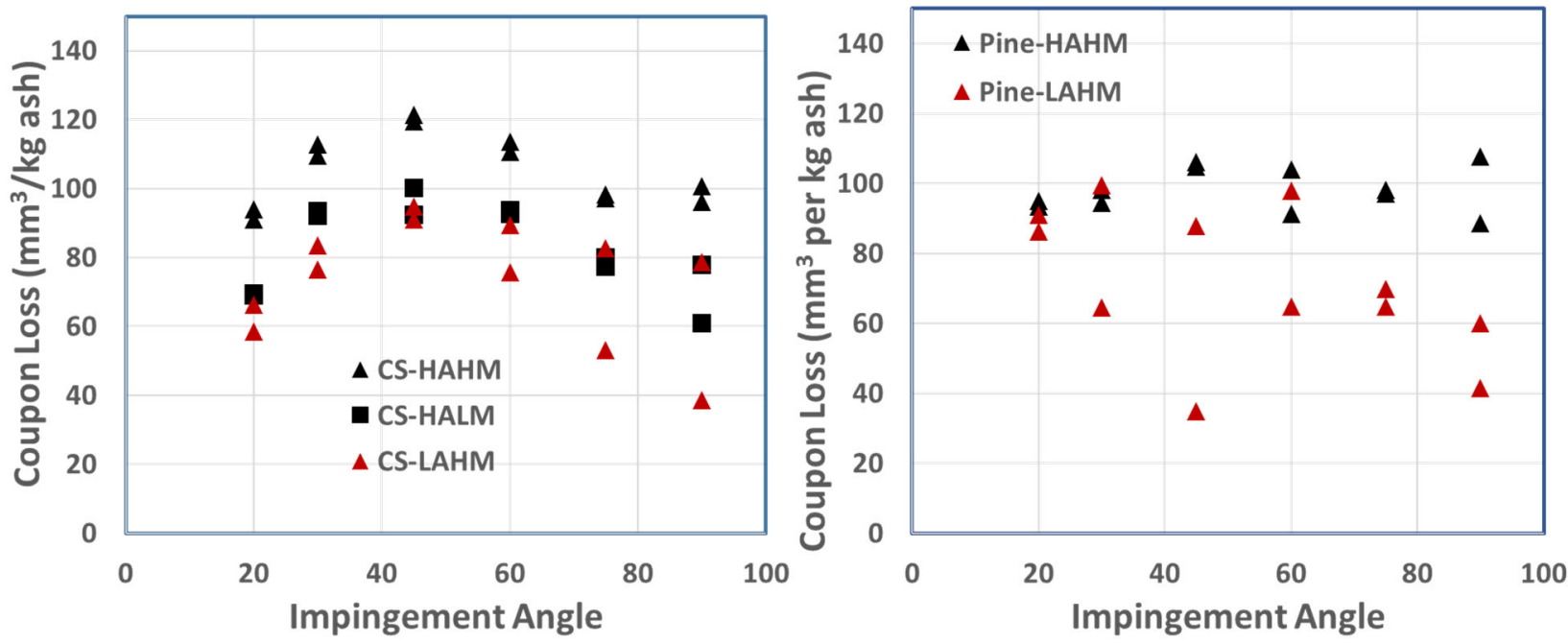

FIGURE 11 Coupon wear rate derived from INL AWT wear tests, assuming a density of $7.8 \mathrm{~g} / \mathrm{cm}^{3}$ for coupon material. Wear data for LALM corn stover were not available, nor was ash content for AWT LM pine residue runs.

\subsection{PARTICLE SIZE DISTRIBUTION}

Validation of the analytical model (Eq. 1-3) against the experimental INL AWT simulation test results (Figure 10) requires information on particle size and speed for the different feedstocks and test conditions (air pressure) used in the tests. Using the analytical technique developed at ORNL [9] to separate inorganic mineral particles from organic constituents of corn stover and pine residue, researchers at ORNL measured the diameter and aspect ratio of individual mineral particles of feedstocks typical of those used in the INL AWT tests. Each dataset (one each for high-ash corn stover, low-ash corn stover, high-ash pine residue, and low-ash pine residue) contained data on 2,000 to 3,000 individual particles. The individual particle sizes were "binned" into 250 inividual bins, each $10 \mu \mathrm{m}$ wide. Figure 12 shows an example of the particle size distribution of inorganic mineral ash in low-ash corn stover used in the INL AWT tests. 
Information on the average and standard deviation of the particle diameters is presented in Table 1. The ash content of the corn stover was on average larger than that of the pine residue, and the distribution was more asymetrical than that of the pine residue. Also included in Table 1 are the geometric mean and the geometric standard deviation used for lognormal distributions.

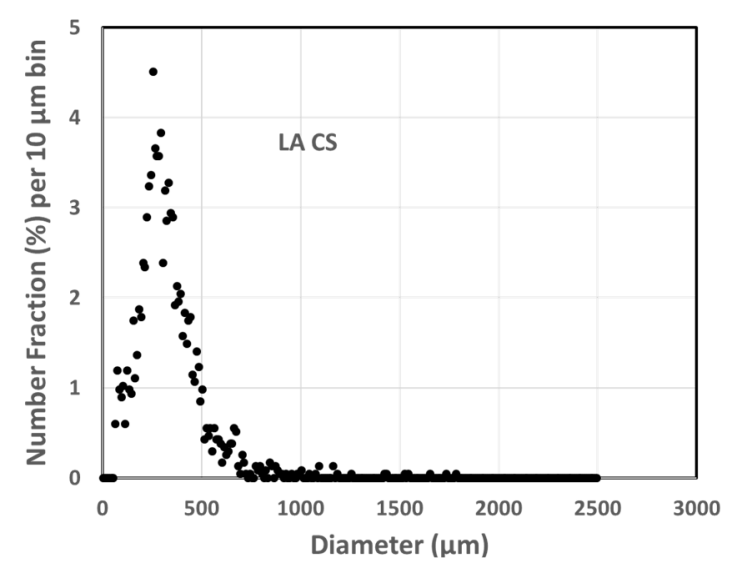

FIGURE 12 Measured particle size distribution of inorganic particles in lowash corn stover $(2,350$ particles analyzed $)$.

TABLE 1 Average, standard deviation, skewness, and kurtosis of inorganic particle size distributions

\begin{tabular}{ccccc}
\hline & $\begin{array}{c}\text { Low-Ash } \\
\text { Corn Stover }\end{array}$ & $\begin{array}{c}\text { High-Ash } \\
\text { Corn Stover }\end{array}$ & $\begin{array}{c}\text { Low-Ash } \\
\text { Pine Residue }\end{array}$ & $\begin{array}{c}\text { High-Ash } \\
\text { Pine Residue }\end{array}$ \\
\hline Average diameter, $d_{\text {avg }}(\mu \mathrm{m})$ & 326 & 394 & 194 & 193 \\
Standard deviation, $\sigma(\mu \mathrm{m})$ & 168 & 218 & 205 & 203 \\
Geometric mean, $d_{g}(\mu \mathrm{m})$ & 290 & 351 & 144 & 142 \\
Geometric standard deviation, $\sigma_{g}(\mu \mathrm{m})$ & 1.65 & 1.62 & 1.52 & 1.54 \\
\hline
\end{tabular}

The experimenatal size distributions were fitted to several different mathematical forms including a normal (Gaussian) distribution, a lognormal distribution in which the sizes are distributed normally on a logrythmic scale, and a hybrid bimodal function (normal + lognormal) distribution.

The normal (Gaussian) distribution is repersented by

$$
f\left(\mathrm{~d}, d_{\text {avg }}, \sigma\right)=\frac{1}{\sigma \sqrt{2 \pi}} e^{-\frac{\left(d-d_{\text {avg }}\right)^{2}}{2 \sigma^{2}}}
$$

where $d, d_{\text {avg }}$, and $\sigma$ are the diameter, average diameter, and standard deviation, respectively.

For a lognormal distribution, the distribution is given as:

$$
f\left(d, d_{g}, \sigma_{g}\right)=\frac{1}{d * \ln \left(\mu_{g}\right) * \sqrt{2 \pi}} e^{-\frac{\left(\ln (d)-\ln \left(d_{g}\right)\right)^{2}}{2\left(\left(\ln \left(\sigma_{g}\right)\right)^{2}\right.}}
$$


where $d, d_{g}$, and $\sigma_{g}$ are the diameter, geometric mean, and geometric standard deviation, respectively [25].

As shown below, the normal and lognormal distributions (Eq. 7 and 8) did not adequately replicate the experimental distributions; thus a third hybrid, bimodal approach was selected to model the distributions. The hybrid model is given as

$$
f(d, A, B, C, A A, B B, C C)=\frac{\boldsymbol{A}}{\boldsymbol{B} \sqrt{2 \pi}} e^{-\frac{(d-C)^{2}}{2 \sigma^{2}}}+\frac{\boldsymbol{A A}}{d * \mathbf{B B} * \sqrt{2 \pi}} e^{-\frac{(\ln (d)-C C)^{2}}{2\left(\left(\ln \left(\sigma_{g}\right)\right)^{2}\right.}}
$$

where $d$ is the diameter ( $\mu \mathrm{m})$ and the constants $A, A A, B, B B, C$, and $C C$ were obtained by minimizing the variable, sum of $c h i^{2}$, defined as the difference between $f$ (Eq. 9) and the experimental value:

$$
c h i^{2}=\left(f_{\text {exp }}-f_{\text {norm-lognorm }}\right)^{2}
$$

where $f_{\exp }$ is the experimental number fraction (Figure 12 ), and $f_{\text {norm-lognormal }}$ is the predicted number fraction from Eq. 9.

Results of the exercise to fit the experimental size distributions to the normal, lognormal, and bimodal normal/lognormal forms are summarized graphically in Figure 13 for high- and low-ash corn stover and pine residue feedstocks. The experimental data are shown in black, while the normal and lognormal fits (based on data in Table 1) are shown in blue (normal) and red (lognormal). The hybrid (normal and lognormal) distributions are shown in gold. The following should be noted about the distributions:

- The size distribution for corn stover is unimodal (one peak), while the distribution for the pine residue appears bimodal.

- The peak size for corn stover is approximately $300 \mu \mathrm{m}$, while the peak for pine residue is significantly lower (approximately $100 \mu \mathrm{m}$ )

- The normal distributions are too broad compared to the experimental profiles and do not capture the peak values accurately. The lognormal distributions underestimate the location of the peak for corn stover and overestimate the location of the peak for pine residue.

- The bimodal hybrid distribution (gold) provides a better fit to the data and is better suited to capture peak locations for bimodal distributions such as those observed for pine residue. 

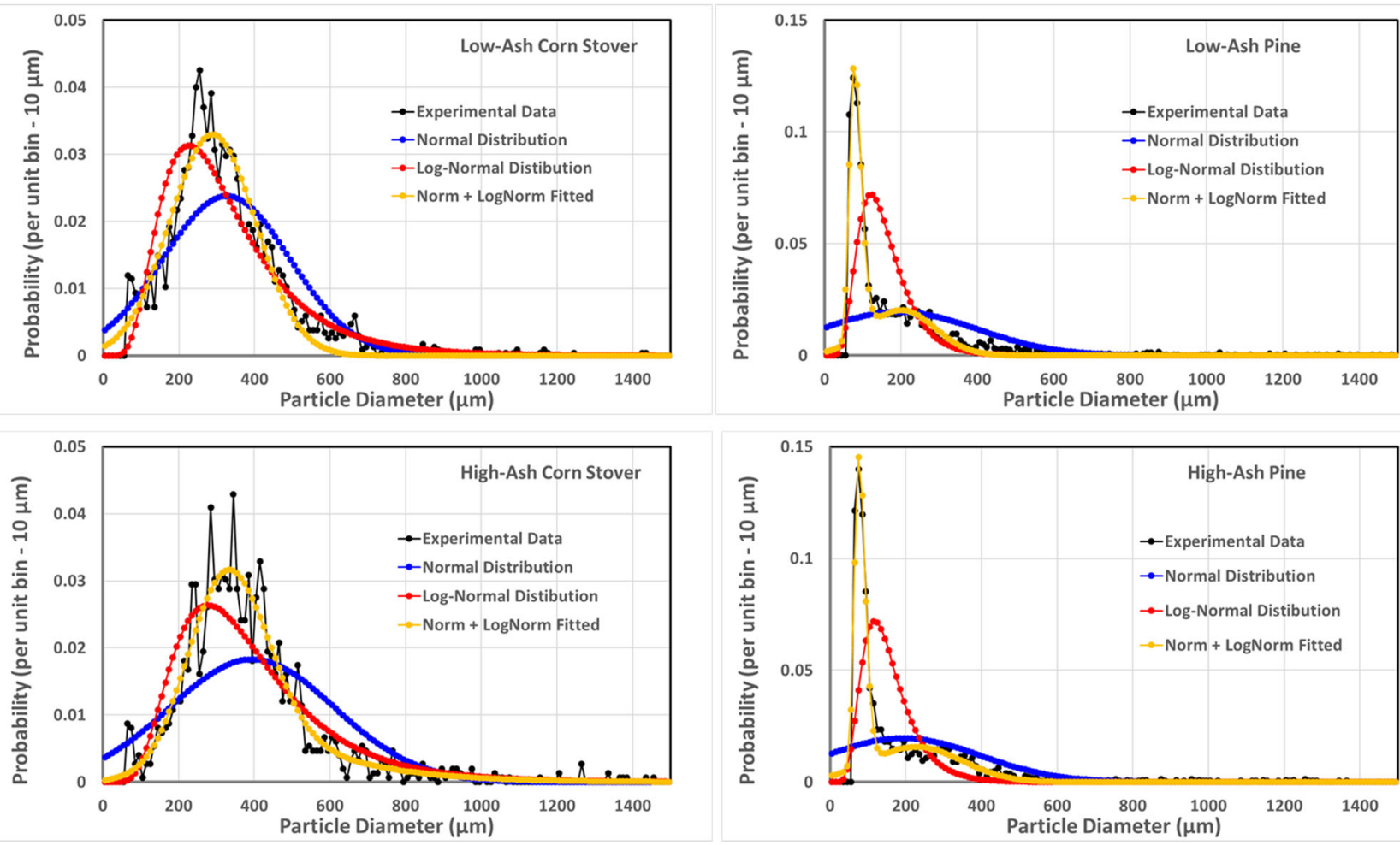

FIGURE 13 Particle size distributions of corn stover and pine residue feedstock: experimental and mathematical fits to data. Note change in y axis for corn stover and pine residue.

\subsection{PARTICLE VELOCITY/SPEED}

Both the cutting and deformation wear rates, $\mathrm{Q}_{\mathrm{C}}$ and $\mathrm{Q}_{\mathrm{D}}$, are dependent on the particle speed, $U_{o}$ (Eq. 2 and 3). Information on the speed of particles exiting the grit blaster nozzle is not obvious, nor can it be calculated based on first principles. Two approaches were used to quantify/bound the particle speeds exiting the nozzle; one involved direct measurement of the motion of individual particles using a high-speed camera installed on the AWT rig, while the second approach assumed the particles flow with the same speed as the air transporting the particles through the nozzle.

Data [26] on the speed of particles as they exit the nozzle of the AWT wear simulator were provided by INL. The data measurements were obtained through use of a high-speed imaging system attached to the AWT simulator. The material used in the simulation runs was prescreened by size (\#12, 1.68-mm opening; \#16, 1.18-mm ; \#20, 0.85-mm; \#40, 0.425-mm; and PAN, 0.1-mm) and separated by type (chips, bark, and needles for pine residue, and husks, cob, stalks, and sheath for corn stover) to obtain speed data as a function of size and type. Analysis of the particle speed is shown graphically in Figures 14 and 15 for corn stover and pine residue, respectively. Typically, 3-4 particles were tracked for each data point with an overall average of $130 \mathrm{~m} / \mathrm{s}$ for corn stover particles and $120 \mathrm{~m} / \mathrm{s}$ for pine residue. The terminology "center" or "angle" refers to particles flowing on-center of the nozzle, while angle refers to particles flowing 
at an angle off-center of the nozzle. Particles flowing off-center (angle) have slightly lower speeds than particles flowing on-center.

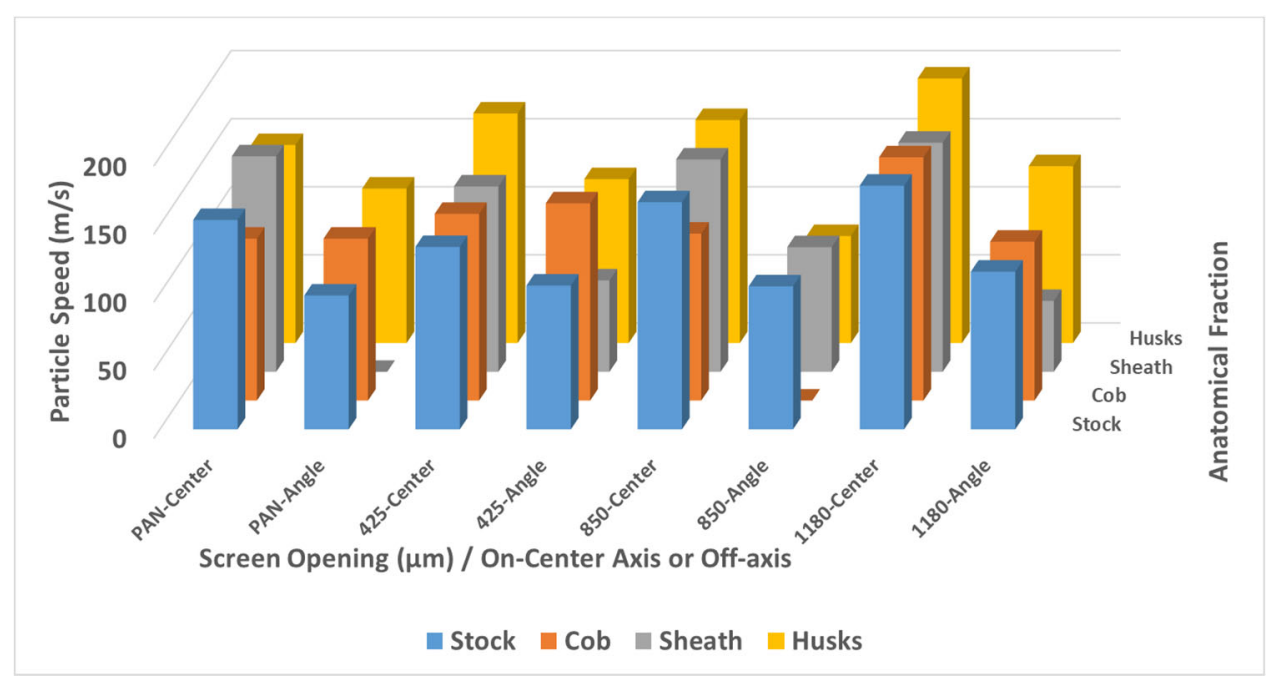

FIGURE 14 Speed of corn stover particles exiting grit blaster nozzle (at 65 psig)

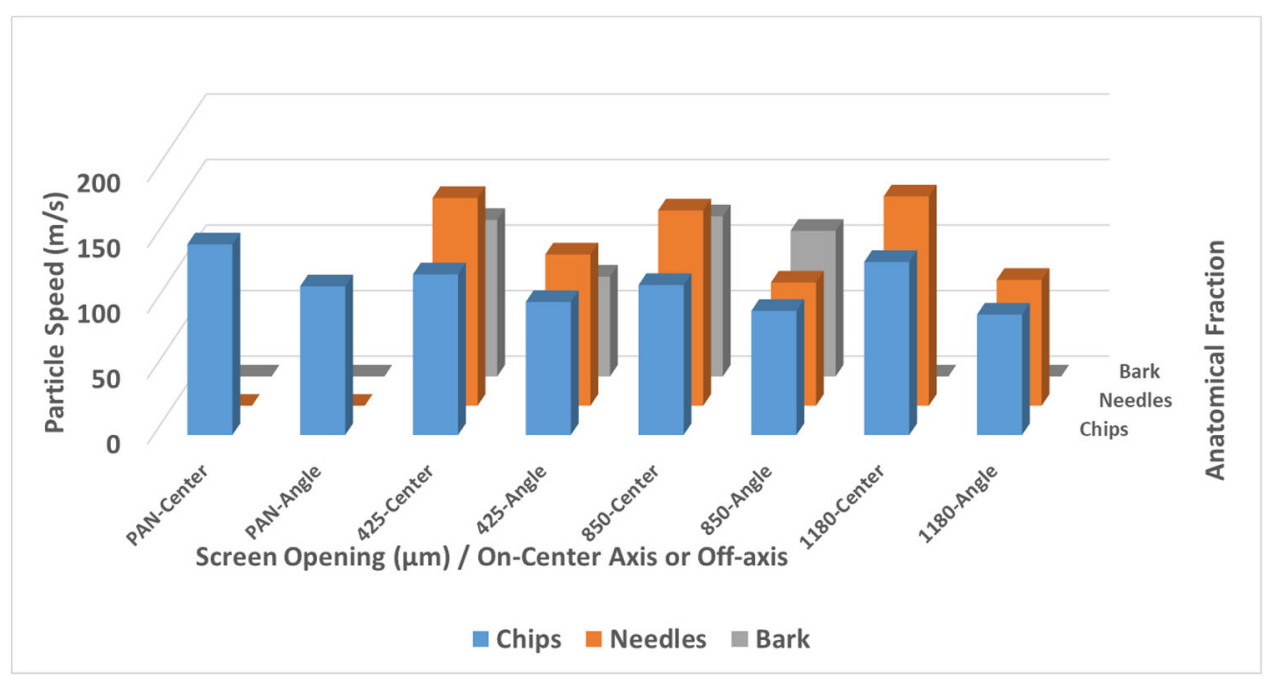

FIGURE 15 Speed of pine residue particles exiting grit blaster nozzle (at 65 psig) 
Analysis of velocity calculations of air mass flow results [27] are summarized in Table 2. These results are based on the time for the pressure in the tank (tank volume $16.04 \mathrm{ft}^{3} / 454.2$ liters) used to feed the inlet of AWT nozzle at 65 psig. The diameter of the nozzle is $4.5 \mathrm{~mm}$ (cross-sectional area $0.15904 \mathrm{~cm}^{2}$ ). At the target/test coupon, the air/particle flow (which is assumed to expand to $1 \mathrm{~atm}$ ) spreads out and covers an area of approximately $7 \mathrm{~mm}$ (area $0.385 \mathrm{~cm}^{2}$ ).

\section{TABLE 2 Estimation of air speed at nozzle exit and coupon face}

\begin{tabular}{|c|c|c|c|c|c|c|c|c|}
\hline $\begin{array}{c}\text { Pressure } \\
\text { (psig) }\end{array}$ & $\begin{array}{c}\text { Tank } \\
\text { Vol } \\
\text { (liters) }\end{array}$ & $\begin{array}{c}\text { Mass of } \\
\text { Air } \\
\text { (moles) }\end{array}$ & $\begin{array}{l}\text { Discharge } \\
\text { Time } \\
(\mathrm{sec}) \\
(\Delta 10 \mathrm{psi}) \\
\end{array}$ & $\begin{array}{c}\text { Mass Flow } \\
\text { Rate } \\
\text { (moles/s) }\end{array}$ & $\begin{array}{l}\text { Vol Flow } \\
\text { Rate at } \\
65 \mathrm{psig}^{\mathrm{a}} \\
\left(\mathrm{cm}^{3} / \mathrm{sec}\right)\end{array}$ & $\begin{array}{c}\text { Linear } \\
\text { Velocity }(\mathrm{m} / \mathrm{s}) \\
\text { at Nozzle } \\
(65 \mathrm{psig})\end{array}$ & $\begin{array}{c}\text { Vol Flow } \\
\text { Rate at } \\
0 \mathrm{psig}^{\mathrm{c}} \\
\left(\mathrm{cm}^{3} / \mathrm{sec}\right)\end{array}$ & $\begin{array}{l}\text { Linear } \\
\text { Velocity } \\
\text { (m/s) at } \\
\text { Coupon }^{\mathrm{d}} \\
(0 \text { psig })\end{array}$ \\
\hline 170 to 160 & 454.2 & 12.46 & 32 & 0.389 & 1589 & 100 & 8722 & 227 \\
\hline 160 to 150 & 454.2 & 12.46 & 34 & 0.366 & 1495 & 94 & 8209 & 213 \\
\hline 150 to 140 & 454.2 & 12.46 & 42 & 0.297 & 1210 & 76 & 6645 & 173 \\
\hline
\end{tabular}

a Volume flow rate at $65 \mathrm{psig}=$ mole flow rate $\times 22.4 \mathrm{~L} / \mathrm{mole} / 65 \mathrm{psig}$ (in atm).

b Linear velocity $=$ volumetric flow/nozzle area.

c Volume flow rate at $1 \mathrm{~atm}(0 \mathrm{psig}$, i.e., at coupon face $)=$ mole flow rate $\times 22.4 \mathrm{~L} / \mathrm{mole} / 1 \mathrm{~atm}$.

d linear velocity at coupon $(1 \mathrm{~atm})=$ volumetric flow (@ coupon face/expanded flow cone (assumed to be $7 \mathrm{~mm}$ )

With the regulator controlling the pressure in the nozzle at $65 \mathrm{psig}$, the times required for the tank pressure to drop from 170 to $160 \mathrm{psig}$, then from 160 to $150 \mathrm{psig}$, and finally from 150 to 140 psig were recorded. When the pressure fell below 140 psig, the compressor kicked in and ran until the pressure exceeded $170 \mathrm{psig}$, at which point the compressor turned off. Based on the tank volume and discharge times, the mass flow rate was approximately 0.3 to $0.4 \mathrm{moles} / \mathrm{s}$. At the nozzle exit (4.5-mm diameter), where the pressure is $65 \mathrm{psig}$, the volumetric flow rate is 1200 to $1,600 \mathrm{~cm}^{3} / \mathrm{s}$, or a linear flow rate through the $4.5-\mathrm{mm}$ nozzle of 75 to $100 \mathrm{~m} / \mathrm{s}$. At the face of the coupon, the pressure is assumed to be at $1 \mathrm{~atm}$; the flow has spread out to a size of 7$8 \mathrm{~mm}$; and the volumetric flow rates (at atm) lies between 6,500 and $8,700 \mathrm{~cm}^{3} / \mathrm{s}$, or linear flow rates between 175 and $225 \mathrm{~m} / \mathrm{s}$.

A comparison of the back-of-the envelope estimates of the speed based on the measured mass flow rate at the face of the test coupon (Table 2) with the measured speed using high-speed imaging (150 to $200 \mathrm{~m} / \mathrm{s}$ ) shows fairly good agreement, and thus the calculations of the predicted wear rates (Eq. 2 and 3) will be performed at a range of speeds ranging from 50 to $250 \mathrm{~m} / \mathrm{s}$ to bracket the range of speeds measured. 


\subsection{MATERIAL PROPERTIES}

Material properties required for the model include hardness, fracture toughness, fatigue ductility (coefficient and exponent of the substrate/test coupons), and density and shape/aspect ratio of the particles. While detailed analysis of the inorganic particles was available, we assume the particles are quartz, $\mathrm{SiO}_{2}$, with a density of $2,600 \mathrm{~kg} / \mathrm{m}^{3}$. The aspect ratio, obtained from the ORNL data on particle size, ranged from approximately 0.5 to 1.0 , with an average value of 0.8 $(0.13 \sigma)$.

The material properties of the test coupons (extracted from stage 1 hammers) were obtained from a variety of sources; some were obtained from metallurgical characterization of the coupons, while others were obtained from commercial material property databases (ANSYS/GRANT CES Selector 2020). Hardness and fatigue ductility were measured; however, measurements of experimental toughness made from Charpy-V (subsized) coupons extracted from actual hammers were questionable because of the limited coupon size (sample thickness), and we relied on fracture toughness data from the ANSYS/GRANTA CES database.

ICP (inductively coupled plasma) analysis of the hammers indicated a low carbon content ( 0.14 to $0.18 \mathrm{wt} \%$ ), suggesting the hammers were fabricated from a 1010 or 1020 low-carbon steel. Information on the heat treatment used to process the steel was not provided. The properties are summarized in Table 3 [28].

\section{TABLE 3 Feedstock and Material Properties Used in Abrasion/Erosion Wear Model}

\begin{tabular}{|c|c|c|c|}
\hline CMA & Material & Value & Comments \\
\hline Particle diameter & $\begin{array}{l}\text { Inorganic component of } \\
\text { low-ash corn stover }\end{array}$ & Hybrid normal-lognormal & $\begin{array}{l}\text { From low-ash corn stover } \\
\text { particle size data (ORNL) }\end{array}$ \\
\hline Particle shape factor & & 0.8 & From ORNL data \\
\hline Particle density & $\mathrm{SiO}_{2}$ & $2600 \mathrm{~kg} / \mathrm{m}^{3}$ & Assumed to be $\mathrm{SIO}_{2}$ \\
\hline Hardness & Stage 1 hammer & $400 \mathrm{H}_{\text {knoop }}$ & Measured \\
\hline Fracture toughness & Stage 1 hammer & $20 \mathrm{~kJ} / \mathrm{m}^{2}$ & GRANTA CES 2020 \\
\hline Young's modulus & Stage 1 hammer & $221 \mathrm{GPa}$ & Measured \\
\hline $\begin{array}{l}\text { Fatigue ductility } \\
\text { coefficient }\end{array}$ & Stage 1 hammer & 1.1 & Measured $\left[\ln \left(\mathrm{A}_{\mathrm{o}} / \mathrm{A}\right)\right]$ \\
\hline $\begin{array}{l}\text { Fatigue ductility } \\
\text { exponent }\end{array}$ & Stage 1 hammer & 0.6 & Assumed (0.5-0.7) \\
\hline
\end{tabular}




\subsection{MODEL PREDICTIONS}

By using the particle size distributions from Figure 13, the material and feedstock properties from Table 3, and estimated particle speeds (up to $250 \mathrm{~m} / \mathrm{s}$ ), an Excel spreadsheet was developed to calculate predicted wear rate $\left(\mathrm{mm}^{3} / \mathrm{kg}_{\text {ash }}\right)$ as functions of impingement angle and compared to measured wear rates from the INL AWT simulation tests. Results of the calculations are shown in Figure 16 for high- and low-ash corn stover and high- and low-ash pine residue. The corn stover curves exhibit the traditional impingement angle dependence, showing a peak rate at intermediate angles around $45^{\circ}$. The predicted curves for the pine residue, however, do not show a peak at intermediate angles and continuously increase as the impingement angle increases from 0 to $90^{\circ}$. This can be explained in terms of the particle size distribution for pine residue (Figure 13), and the dependence of $Q_{C}, Q_{D}$, and $Q_{T}$ on particle size, as discussed in Figure 8, where the shape of $Q_{T}$ is dominated by $Q_{D}$ for small-diameter particles.
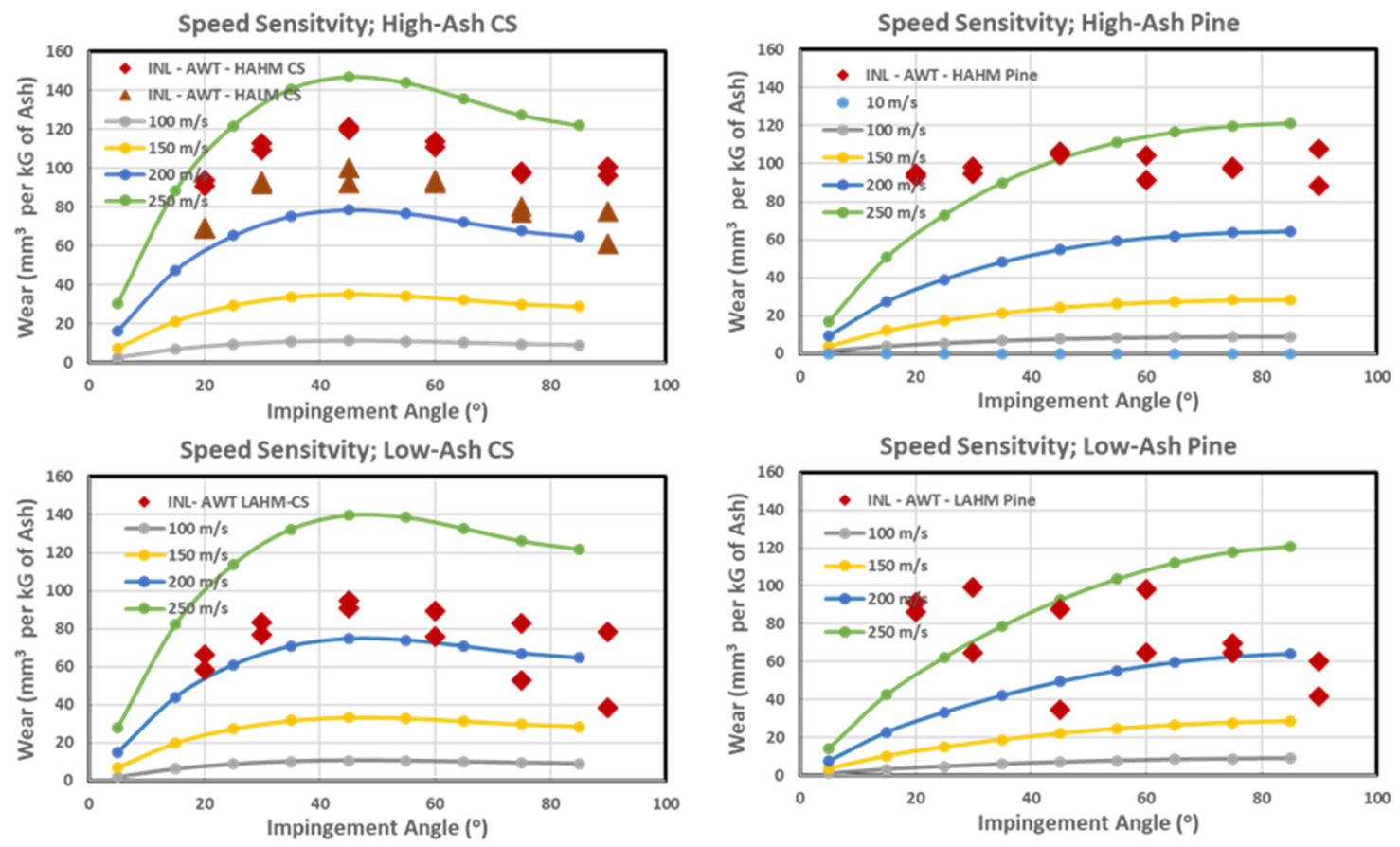

FIGURE 16 Comparison of predicted wear (curves) and measured wear (symbols) for corn stover and pine residue $\left(b, 0.6 ; R, 20 \mathrm{~kJ} / \mathrm{m}^{2} ; \epsilon f, 1.1 ; \eta, 0.8\right)$

Also shown in Figure 16 are the measured wear rates obtained from the INL accelerated wear test rig for corn stover and pine residue feedstocks. The agreement between predicted and measured is good for corn stover, in terms of both magnitude and shape. The agreement for pine residue is good in terms of magnitude, although not as good in terms of shape. 
In order to understand how the material properties, affect the magnitude and shape of the predicted wear rates, a series of sensitivity studies was performed. Material properties that were varied (one-by-one while holding the remaining properties constant) are listed in Table 4 along with the range of variables considered. The baseline conditions are those used for Figure 16 for the high-ash corn stover. Results of the sensitivity study are shown in Figures 17-21 and summarized in Table 5. The baseline condition for each case/figure is highlighted in blue.

\section{TABLE 4 Sensitivity Variables}

\begin{tabular}{lll}
\hline \multicolumn{1}{c}{ Variable } & \multicolumn{1}{c}{ Baseline } & \multicolumn{1}{c}{ Sensitivity Range } \\
\hline Hardness $(H)$ & $3.93 \mathrm{GPa}$ & $3.53 .93 .4 .5,5.0$ \\
Toughness $(R)$ & $20 \mathrm{~kJ} / \mathrm{m}^{2}$ & $10,20,30,100$ \\
Fatigue ductility coefficient $\left(\varepsilon_{\mathrm{f}}\right)$ & 1.1 & $0.8,0.9,1.0,1.1$ \\
Fatigue ductility exponent $(b)$ & 0.6 & $0.55,0.6,0.65,0.7$ \\
Particle shape factor $(\eta)$ & 0.8 & $0.6,0.7,0.8,0.9$ \\
\hline
\end{tabular}
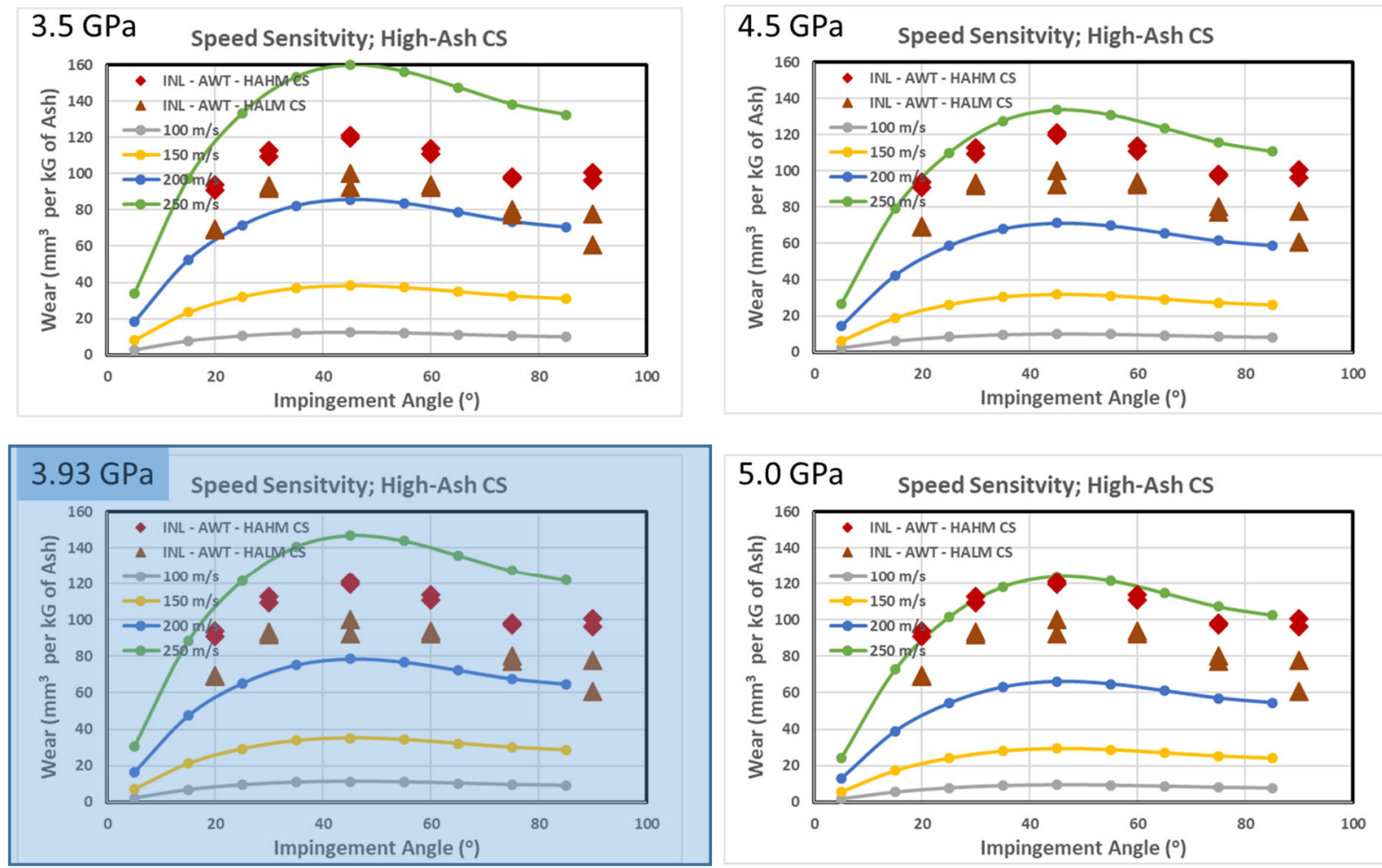

FIGURE 17 Sensitivity study on effect of hardness on predicted wear rate of high-ash corn stover (see Table 4 for conditions). 
10 kJ/m2 Speed Sensitvity; High-Ash Cs
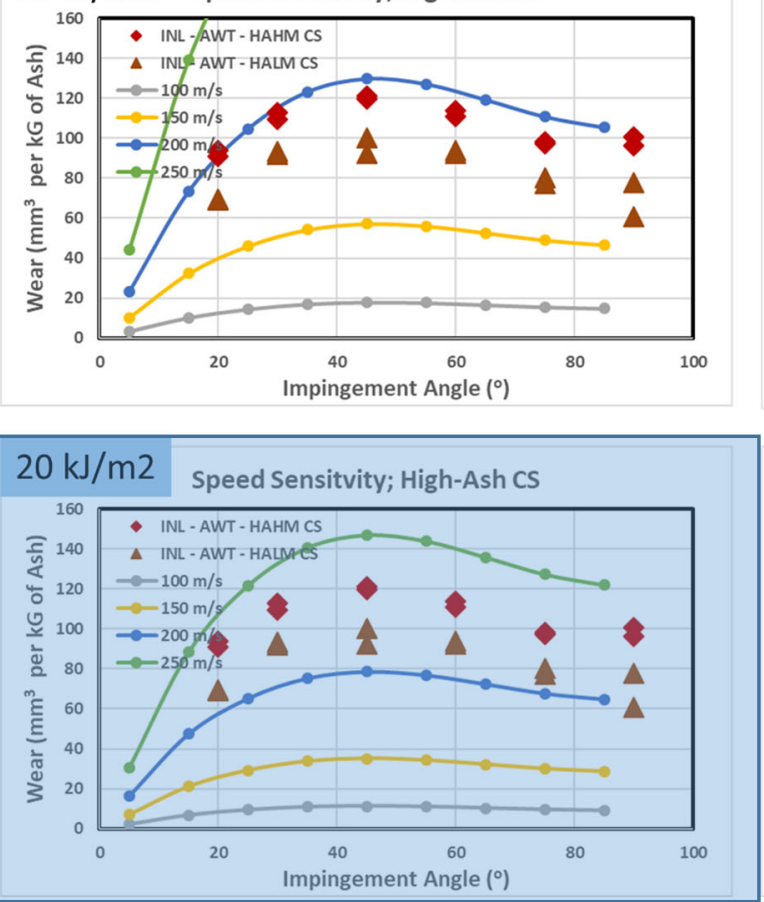

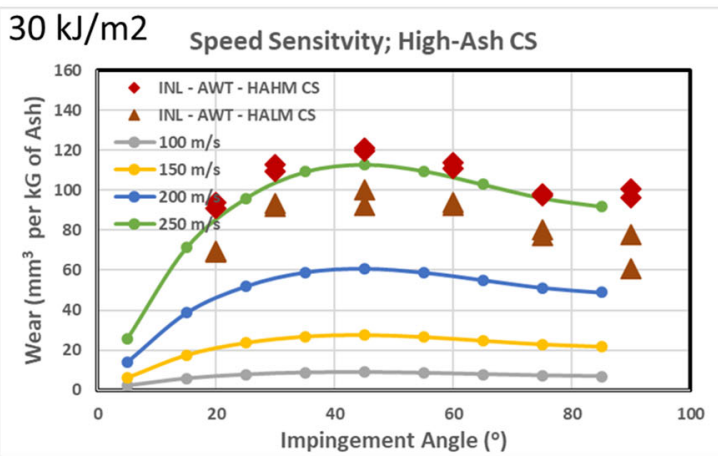

100 kJ/m2 speed Sensitvity; High-Ash CS

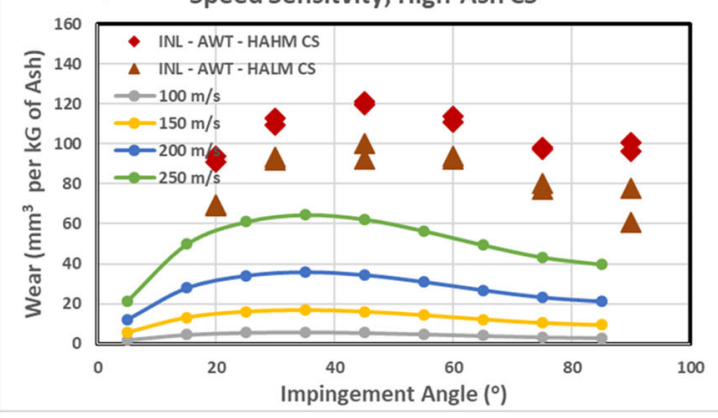

FIGURE 18 Sensitivity study on effect of toughness on predicted wear rate of high-ash corn stover (see Table 4 for conditions).
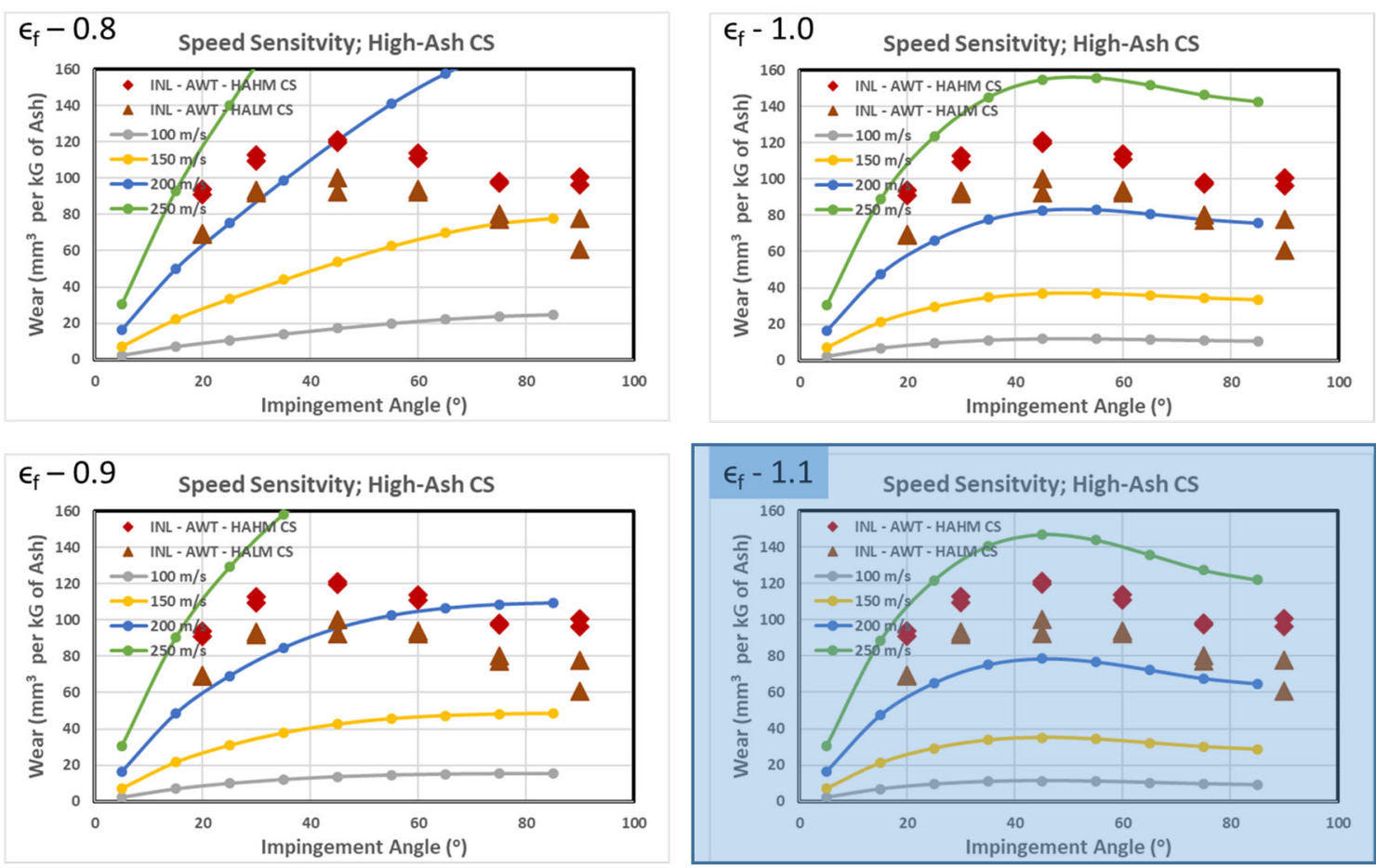

FIGURE 19 Sensitivity study on effect of fatigue ductility coefficient on predicted wear rate of high-ash corn stover (see Table 4 for conditions). 
b - 0.55 Speed Sensitvity; High-Ash CS
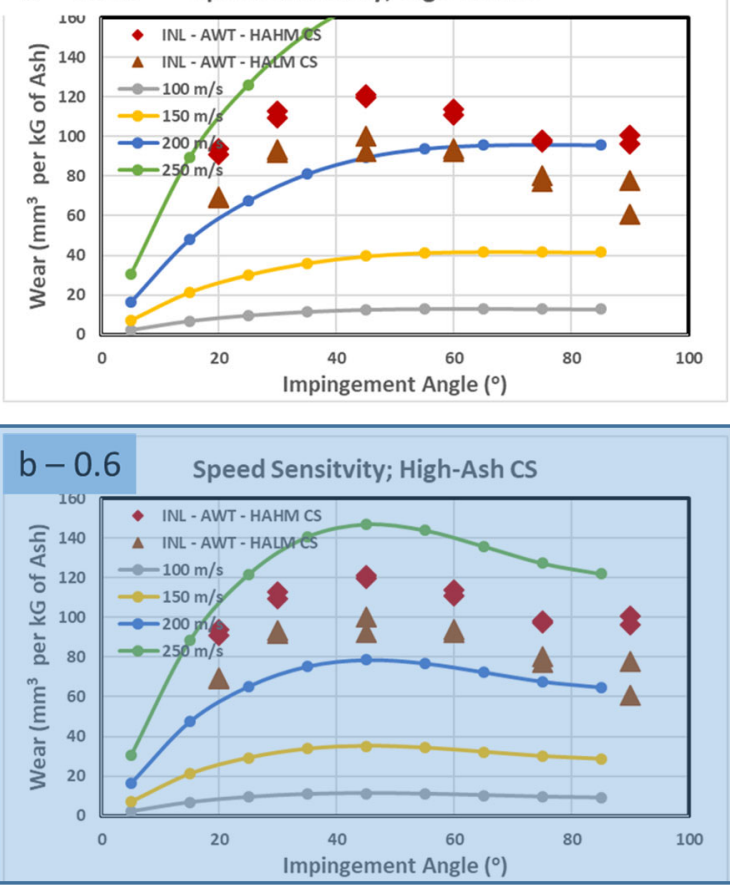

b - 0.65 Speed Sensitvity; High-Ash CS

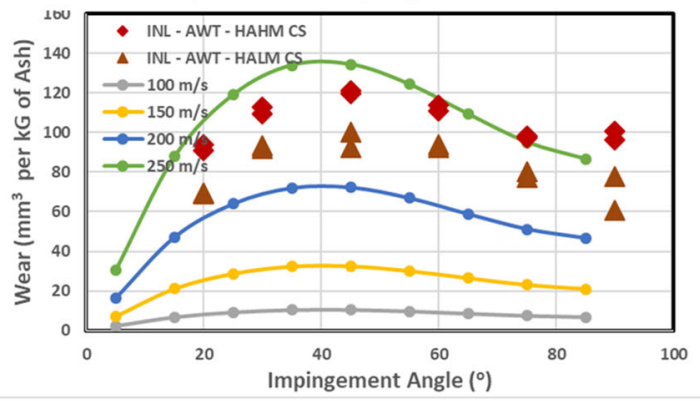

b - $0.7 \quad$ Speed Sensitvity; High-Ash CS

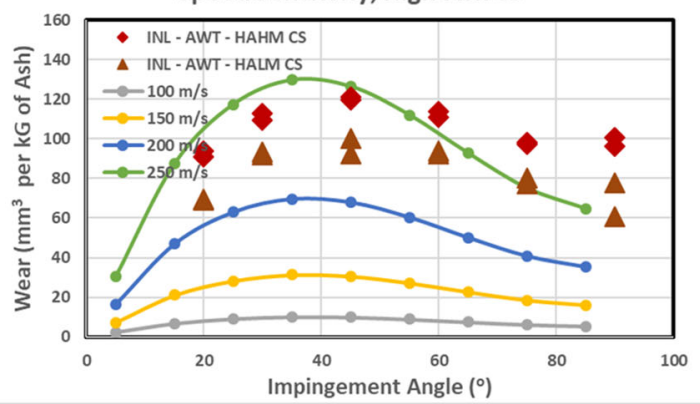

FIGURE 20 Sensitivity study on effect of fatigue ductility exponent on predicted wear rate of high-ash corn stover (see Table 4 for conditions).
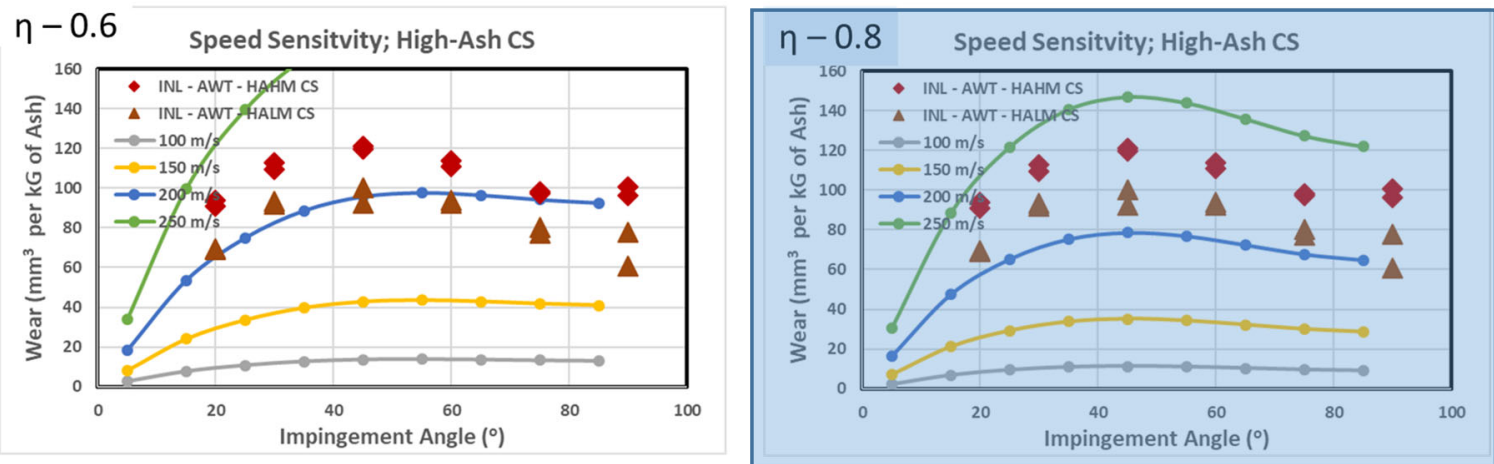

$\eta-0.7 \quad$ Speed Sensitvity; High-Ash CS
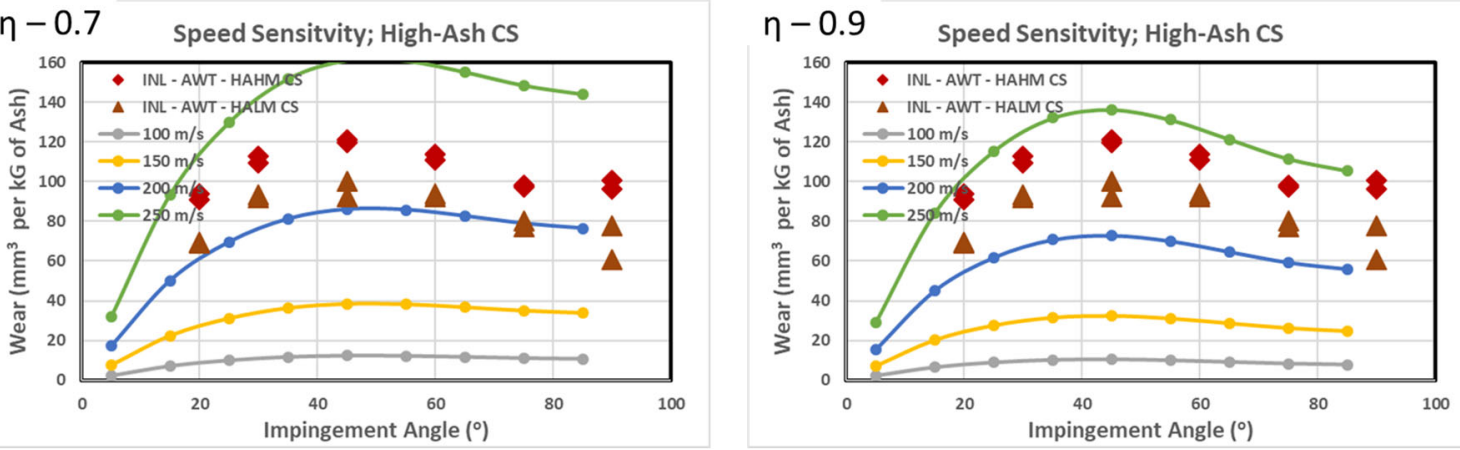

FIGURE 21 Sensitivity study on effect of particle shape factor on predicted wear rate of high-ash corn stover (see Table 4 for conditions). 
TABLE 5 Effect of variables on wear behavior

\begin{tabular}{|c|c|c|c|}
\hline Variable & Sensitivity & $\begin{array}{c}\text { Impact on Wear } \\
\text { (magnitude) } \\
\text { Compared to Baseline }\end{array}$ & $\begin{array}{c}\text { Physical Appearance of Wear } \\
\text { versus Impingement } \\
\text { (unimodal versus monotonic } \\
\text { increase) }\end{array}$ \\
\hline Hardness & Increasing hardness... & Decreases wear rate... & No effect on shape \\
\hline Toughness & Increasing toughness... & Decreases wear rate.. & No effect on shape \\
\hline Fatigue ductility & Decreasing $\epsilon_{\mathrm{f}} \ldots$. & Increases wear rate $\ldots$ & $\begin{array}{l}\text { Transition from unimodal to } \\
\text { monotonically increasing }\end{array}$ \\
\hline \multirow[t]{2}{*}{ Fatigue ductility } & Increasing $b \ldots$ & Slightly decreases wear & Accentuates unimodal peak \\
\hline & Decreasing b ... & Slightly decreases wear & $\begin{array}{l}\text { Transitions to monotonically } \\
\text { increasing }\end{array}$ \\
\hline \multirow[t]{2}{*}{ Shape factor } & Increasing $\eta \ldots$ & Slightly decreases wear & $\begin{array}{l}\text { Slight change in shape, } \\
\text { transitioning to monotonic } \\
\text { behavior as } \eta \text { decreases }\end{array}$ \\
\hline & Decreasing $\eta \ldots$ & Slightly decreases wear & $\begin{array}{l}\text { Slight change in shape, } \\
\text { transitioning to monotonic } \\
\text { behavior as } \eta \text { decreases }\end{array}$ \\
\hline
\end{tabular}

By further fine-tuning the material properties, better agreement between measured and predicted behavior can be obtained, as shown in Figure 22 for the following variables (for the corn stover):

- Hardness $=3.93 \mathrm{GPa}$, the same as the baseline;

- Fracture toughness $=10 \mathrm{~kJ} / \mathrm{m}^{2}$, versus $20 \mathrm{~kJ} / \mathrm{m}^{2}$ for the baseline case;

- $\quad$ Fatigue ductility coefficient $=1.1$, the same as the baseline case;

- Fatigue ductility exponent $=0.65$, versus 0.6 for the baseline case; and

- Particle shape factor $=0.6$, versus 0.8 for the baseline.

By changing the toughness, fatigue ductility exponent, and shape factor (i.e., changing the effective particle diameter, $\left.d_{e f f}\right)$, the speed for agreement between measured and predicted wear drops from approximately 21 to $175 \mathrm{~m} / \mathrm{s}$. 

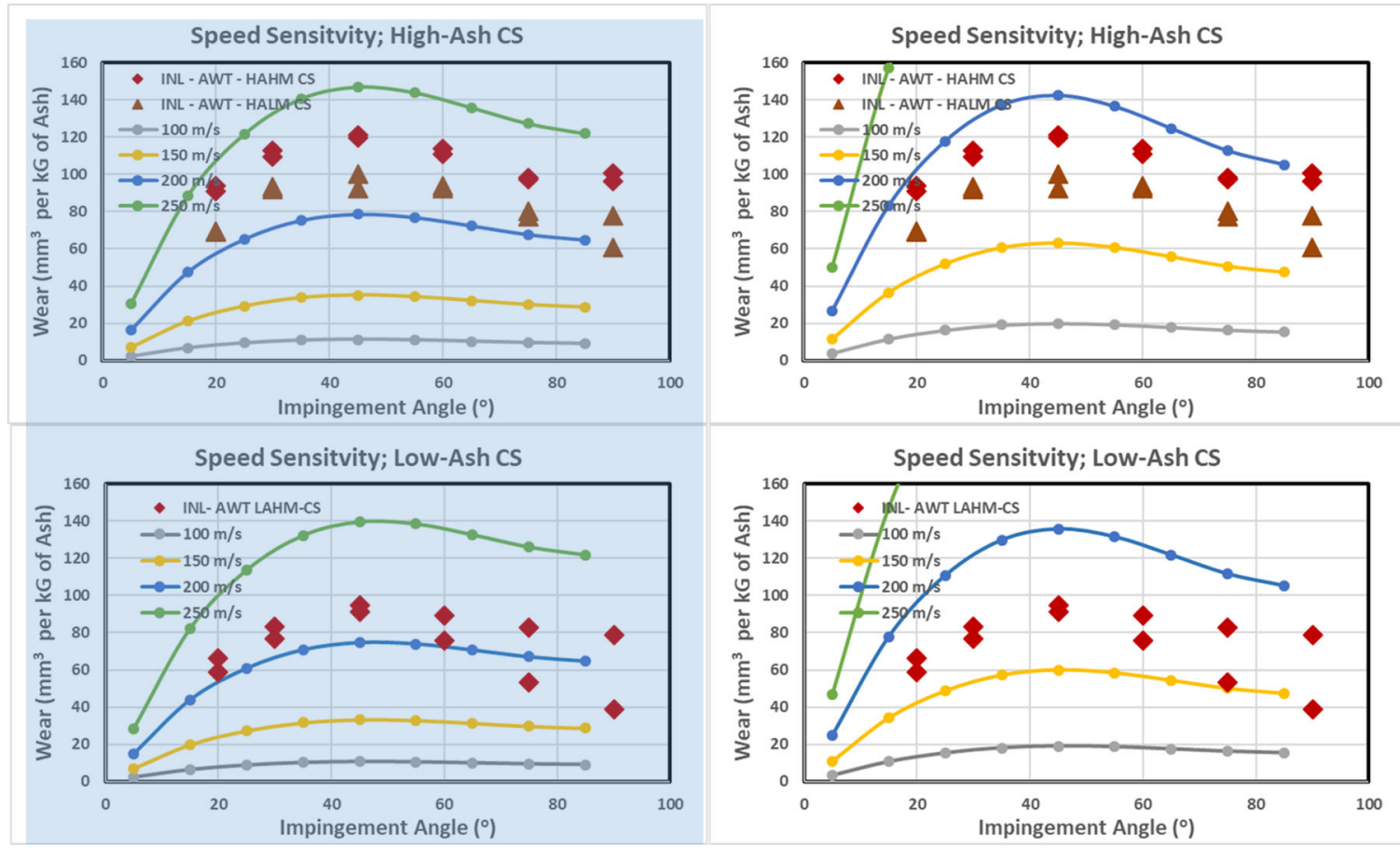

FIGURE 22 Comparison of predicted versus measured wear for high- and low-ash corn stover: (left) baseline, $3.93 \mathrm{GPA} ; 20 \mathrm{~kJ} / \mathrm{m}^{2}$; $\epsilon$, 1.1; b, 0.6; $\eta, 0.8$; and (right) 3.93 GPA; $10 \mathrm{~kJ} / \mathrm{m}^{2} ; \epsilon f, 1.1 ;$ b. $\left.0.65 ; \eta, 0.6\right)$ 


\section{DISCUSSION AND CONCLUSIONS}

An analytical model of erosive wear based on plastic deformation and fatigue impact of near-surface regions was developed to predict wear as a function of CNAs of extrinsic inorganic particles (size, shape, and density) in biomass feedstock, CMAs of alloys used for milling hammers (hardness, fracture toughness, fatigue ductility coefficient and exponent), and critical process parameters (particle speed and impingement angle). The model used a series of constitutive equations developed by Ben-Ami et al. [21] to model erosive wear of materials with two semi-empirical constants, $C_{C}$ and $C_{D}$, used to calculate the volumetric wear rate (cubic millimeters per kilogram of particles) due to deformation processes and cutting processes. The calculations relied on CMAs of the inorganic particles incident on the substrate, CMAs of the substrate, and CPPs. The values of the two semi-empirical parameters, $C_{C}$ and $C_{D}$, were derived from several studies of erosive wear by independent authors for $\mathrm{SiC}$ and $\mathrm{SiO}_{2}$ particles incident on lead, copper, and SAE 1055 steel substrates. Application of the Ben-Ami constitutive model to predict the wear observed in the INL AWT simulation studies revealed the following:

- The distribution in particle sizes was best fit to a hybrid distribution involving a linear combination of normal and lognormal distributions (Eq. 9), Inorganic mineral particles present in pine residue were significantly smaller than particles in corn stover, and pine residue particles showed a bimodal distribution in sizes, while distributions of inorganic corn stover particles were unimodal.

- The particle speed was obtained by direct measurement of individual particles using high-speed imaging or by assuming the particles flowed with the flow of air through the nozzle. Direct measurement of individual particle speeds indicated speeds ranging from approximately $30 \mathrm{~m} / \mathrm{s}$ to more than $250 \mathrm{~m} / \mathrm{s}$, with average speeds of 100 to $170 \mathrm{~m} / \mathrm{s}$ for particles less than $850 \mu \mathrm{m}$. Particle speed estimates based on mass flow suggest speeds ranging from 170 to $230 \mathrm{~m} / \mathrm{s}$ (Table 2).

- Material properties (hardness, fracture toughness, and fatigue ductility) were either measured or obtained from commercial material property databases such as CES Selector 2020. Results are summarized in Table 3.

- The hardness is fairly straightforward and easy to measure, while fatigue ductility, $\varepsilon f$, can be obtained from reduction in area [29] data obtained from tensile strength measurements (pull to failure).

- Fracture toughness, on the other hand, is complex and dependent on multiple factors (temperature, strain rate, geometry, technique, mode, and sample size, in addition to alloy and heat treatment). An attempt was made to measure fracture toughness using data from Charpy impact tests on coupons extracted from stage 1 hammers. However, the results proved to be unreliable because of the small width of the coupons extracted from the hammers. Consequently, the toughness data used in the wear predictions were obtained from a 
commercial material database, and the values are representative of 1010/1020 low-carbon steels.

- Direct application of the model and constitutive equations using the same semiempirical constants, properties for the corn stover and pine residue feedstocks, properties of the stage 1 hammers used for the INL AWT simulation tests, and measured/inferred particle speeds showed excellent agreement between measured and predicted values - in terms of both magnitude and shape, more so for the corn stover than the pine residue (see Figure 16).

- It is not clear why the experimental wear data for the pine residue (see Figures 11 or 16) as a function of impingement angle are relatively flat compared to the unimodal curves for corn stover that show the traditional peak in wear at intermediate angles. The difference could be attributed to the small size of the inorganic particles (Figure 13), which would diminish the contribution from $Q_{C}$ compared to that from $Q_{D}$ to the overall wear, $\mathrm{Q}_{T}$, as discussed in the text for Figure 8. Alternatively, note that the ash content of the pine residue was significantly lower than the ash content of the corn stover, and the erratic nature of the experimental pine residue wear data was in part due to poor statistics. The AWT runs used approximately $500 \mathrm{~g}$ of feedstock for each run. For corn stover, the ash content ranged from 50 to $80 \mathrm{~g}$ of ash per $500 \mathrm{~g}$ of feedstock; for pine residue, the ash content ranged from 2 to $8 \mathrm{~g}$ of ash per $500 \mathrm{~g}$ of feedstock, significantly less than that of the corn stover. This was reflected in the wear measurements (weight/mass loss), which ranged from 50 to $80 \mathrm{mg}$ (out of an initial coupon mass of approximately $30 \mathrm{~g}$ ) for corn stover, compared to mass losses of 2 to $8 \mathrm{~g}$ for the pine residue. If time permits, it would be interesting to perform tests using feedstock mass adjusted for constant ash content (say, $100 \mathrm{~g}$ ash) rather than a constant feedstock content.

\subsection{FUTURE DIRECTIONS}

Future activities will focus on the following tasks:

- Application of the model to predict geometrical wear patterns of hammer wear from stage 1 hammermill, and

- Development of a tool to connect the Ben-Ami wear model to materials database to optimize material specifications.

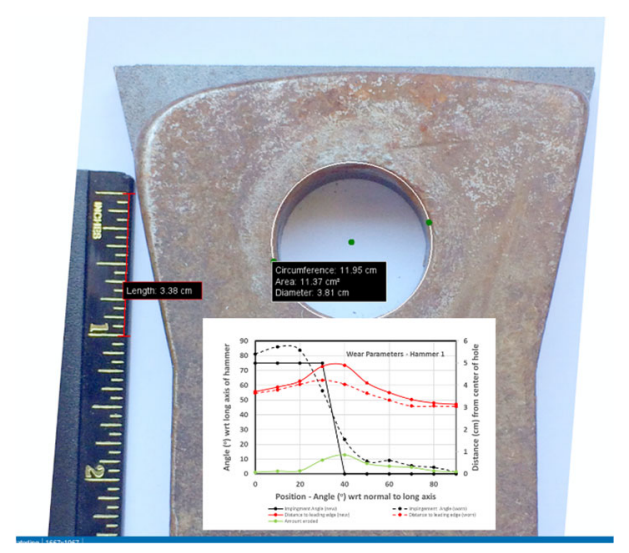




\section{REFERENCES}

[1] Office of Energy and Efficiency \& Renewable Energy, 2020,"Bioenergy Technologies.” Available at https://www.energy.gov/eere/bioenergy.

[2] Julie Baruah, Bikash Kar Nath, Ritika Sharma, Sachin Kumar, Ramesh Chandra Deka, Deben Chandra Baruah, and Eeshan Kalita, 2018, "Recent Trends in the Pretreatment of Lignocellulosic Biomass for Value-Added Products," Frontiers in Energy Research 6, article 141. Available at www.frontiersin.org.

[3] Adepu Kiran Kumar and Shaishav Sharma, 2017, "Recent Updates on Different Methods of Pretreatment of Lignocellulosic Feedstocks: A Review," Bioresources and Bioprocessing 4, article 7. DOI 10.1186/s40643-017-0137-9.

[4] Solange Mussatto , ed., 2016, Biomass Fractionation Technologies for a Lignocellulosic Feedstock Based Biorefinery, Elsevier. ISBN: 978-0-12-802323-5

[5] George Fenske and Oyelayo Ajayi, 2019, "Task 1, Materials of Construction Task 1.3, Mechanics of Wear FCIC Milestone Report for FY19 Q2," Argonne National Laboratory, Lemont, IL.

[6] E. Wolfrum, 2019, "Hammer mill," DOE Bioenergy Technologies Office 2019 Project Peer Review, Feedstock-Conversion Interface Consortium (FY2018), Denver, CO, March.

[7] J. Qu, W. Li, and J. Keiser, 2018, "ORNL Contribution to FY18 Q3 Quarterly Progress Report for the FCIC Process Integration Project," WBS 2.2.1.50x.

[8] George Fenske and Oyelayo Ajayi, 2018, “ANL Contribution to FY18 Q4 Quarterly Progress Report for the FCIC Process Integration Project,” WBS 2.2.1.50x.

[9] Kyungjun Lee, Sougata Roy, Ercan Cakmak, Jeffrey A. Lacey, Thomas R. Watkins, Harry M. Meyer, Vicki S. Thompson, James R. Keiser, and Jun Qu, 2020, “CompositionPreserving Extraction and Characterization of Biomass Extrinsic and Intrinsic Inorganic Compounds," ACS Sustainable Chemical Engineering 8: 1599-1610.

[10] Rajan Jog and Diane J. Burgess, 2019, "Comprehensive Quality by Design Approach for Stable Nanocrystalline Drug Products," International Journal of Pharmaceutics 564: 426460.

[11] Jeffrey A. Lacey and Sergio Hernandez, 2020, "Determine Wear Contributions from Anatomical Fractions of Biomass and Extrinsic Ash," Task 1 Materials of Construction FY20 Q1 Milestone Report, Idaho National Laboratory, Idaho Falls, ID. 
[12] Jeffrey A. Lacey, John E. Aston, Sergio Hernandez, Mary Intwan, Vicki S. Thompson, Kyungjun Lee, and Jun Qu, 2019, "Wear and Why? How Ash Elements Can Help Define Wear Profiles of Biomass Feedstocks," presented at 2019 ASABE Annual International Meeting, Boston, MA, July 7-10.

[13] R. Wood, 2017, "Solid Particle Erosion," in Friction, Lubrication, and Wear Technology, ASM Handbook, Vol. 18, G. Totten (editor), ASM International.

[14] D. Li, 2017, "Abrasive Wear," in Friction, Lubrication, and Wear Technology, ASM Handbook, Vol 18, G. Totten (editor), ASM International.

[15] C. Mayer-Laigle, N. Blanc, R. Rajaonarivony, and X. Rouau, 2018, "Comminution of Dry Lignocellulosic Biomass, a Review: Part I, From Fundamental Mechanisms to Milling Behaviour," Bioenginering 5(2): 41.

[16] I. Finnie, 1960, "Erosion of Surfaces by Solid Particles," Wear 3(2): 87-103.

[17] J. G. A. Bitter, 1963, “A Study of Erosion Phenomena part 1,” Wear 6(1): 5-21.

[18] I. M. Hutchings, 1981, "A Model for the Erosion of Metals by Spherical Particles at Normal Incidence," Wear 70 (3): 269-281.

[19] C. Huang, S. Chiovelli, P. Minev, J. Luo, and K. Nandakumar, 2008, Powder Technology 187(3): 273-279.

[20) H. Arabnejad, A. Mansouri, S.A. Shirazi, and B.S. McLaury, 2015, "Development of Mechanistic Erosion Equation for Solid Particles," Wear 332: 1044-1050.

[21] Y. Ben-Ami, A. Uzi, and A. Levy, 2016, "Modelling the Particles Impingement Angle to Produce Maximum Erosion," Powder Technology 301: 1032-1043.

[22] J. Lacey, J. Aston, and V. Thompson, 2018, "Expectation vs. Reality: The Unexpected Abrasive Nature of Biomass Feedstocks," INL/CON-17-44037-Revision-0, presented at Symposium on Biotechnology for Fuels and Chemicals, Clearwater Beach, FL, May.

[23] J. A. Lacey, J. E. Aston, S. Hernandez, and V. S. Thompson, 2019, "Development of an Accelerated Wear Testing Apparatus for Assessing Wear Properties of Biomass Feedstocks," in review.

[24] J. Lacey, 2019, "Sample Info for Coupon Testing," email from J. Lacey (Idaho National Laboratory, Idaho Falls, ID) to K. Lee, Jun Qu, and G. Fenske (Argonne National Laboratory, Lemont, IL), June 24. 
[25] J. C. Ferrari, F. Castilhos, P. H. H. Araújo and C. Sayer, 2016, ”Modeling Particle Size Distribution in Heterogeneous Polymerization Systems Using Multimodal Lognormal Function," Brazilian Journal of Chemical Engineering 33 (03): 469-478. dx.doi.org/10.1590/0104-6632.20160333s20150114.

[26] J. Lacey, 2019, "Excel Spreadsheet on Particle Air Speeds," email from J. Lacey (Idaho National Laboratory, Idaho Falls, ID) to George Fenske (Program Leader, Tribology, Argonne National Laboratory, Lemont, IL), Oct. 15.

[27] Brad Thomas, 2019, "Particle Velocity Update," email from B. Thomas ( ) to George Fenske (Program Leader, Tribology, Argonne National Laboratory, Lemont, IL), Oct. 23.

[28] George Fenske and Oyelayo Ajayi, 2020, "Task 1, Materials of Construction Task 1.3, Mechanics of Wear, FCIC Milestone Report for FY20 Q1,” Argonne National Laboratory, Lemont, IL.

[29] “True Stress and True Strain" https://web.adanabtu.edu.tr/Files/iyilmaz/Duyuru/dosya/ ME\%20207\%20\%E2\%80\%93\%20Chapter\%203_P3.pdf 



\section{Argonne $A$}

\section{Applied Materials Division}

Argonne National Laboratory

9700 South Cass Avenue, Bldg. 362

Lemont, IL 60439-4832

www.anl.gov 